\title{
7. AUF DEM WEG IN DEN KRIEG
}

\subsection{Die Kaltstellung der Konservativen: »une sorte de 30 juin sec«}

Die deutschlandpolitischen Vorstellungen André François-Poncets wurden wie gesehen - nicht nur von der deutschen Außen- und Frankreichpolitik, sondern auch von der deutschen Innenpolitik beeinflußt. Der immer stärker werdende Nationalismus in der untergehenden Weimarer Republik, die Machtübernahme der Nationalsozialisten und die weitere Entwicklung haben immer wieder zu einer Verschlechterung seiner Wahrnehmung Deutschlands geführt, die nicht ohne Folgen für seine deutschlandpolitischen Vorstellungen blieb. Daß der französische Botschafter Deutschland gleichwohl zugewandt blieb, eine Annäherung für möglich hielt, ist auch auf biographische Beweggründe zurückzuführen, die abschließend im Zusammenhang zu betrachten sind. An dieser Stelle ist derweil zu fragen, ob und wie die innenpolitischen Ereignisse der Jahre 1937 und 1938 seine Wahrnehmung Deutschlands beeinträchtigt und damit die deutschlandpolitischen Vorstellungen spürbar verändert haben.

Ausschlaggebend für André François-Poncets Deutschlandperzeption in der Schlußphase seiner Amtszeit war das Revirement an der Spitze der Wehrmacht und des Auswärtigen Amtes in Folge der sogenannten BlombergFritsch-Affäre Anfang Februar 1938 ${ }^{1}$. Die Intrige gegen Kriegsminister Werner von Blomberg, der wegen seiner Mesalliance Ende Januar 1938 zurücktrat, und gegen den Oberbefehlshaber des Heeres Werner Freiherr von Fritsch, der wegen angeblicher Homosexualität entlassen wurde, und schließlich die Beförderung des Außenministers von Neurath zum Präsidenten des Geheimen Kabinettsrates erschienen dem französischen Botschafter wie »une sorte de 30 juin sec « ${ }^{2}$. Die Übernahme des Kriegsministeriums und des Oberbefehls über die Wehrmacht durch Hitler, die Ernennung des Intriganten Hermann Göring zum Generalfeldmarschall und des Londoner Botschafters Joachim von Ribbentrop zum Außenminister kündigten für André FrançoisPoncet im Innern wie im Äußern »un cours plus radical« an: »Les hommes qui sortent vainqueurs de l'épreuve sont des amis fougueux de l'Italie, de l'Espagne nationaliste, du Japon en guerre avec la Chine. Ils sont des adversai-

1 Zu den Hintergründen siehe THAMER, Verführung, S. 564-570 und ausführlich KarlHeinz JANSSEN, Fritz TOBIAS, Der Sturz der Generäle. Hitler und die Blomberg-FritschKrise 1938, München 1994.

2 Telegramme Nr. 616-634 vom 5. Februar 1938, S. 4, in: CADN, Ambassade Berlin, Série B, Carton 158. 
res non moins fougueux de l'Autriche et de la Tchécoslovaquie. Ils réclament dans la conduite des affaires étrangères plus d'énergie et d'audace ${ }^{3}$. Insofern könnte man sich zu Recht Sorgen um den europäischen Frieden gemacht werden, zumindest bis Hitler seine Absichten dargelegt und seinen Friedenswillen bewiesen habe. André François-Poncet glaubte, daß dem Revirement ein Konflikt zwischen dem Oberkommando und der Partei zugrunde liege, der die Frage nach der Orientierung der Reichsregierung wieder aufwerfe. $\mathrm{Da} B$ die Radikalen den Gemäßigten, die Partei dem Oberkommando eine Niederlage beigebracht hatten, schien klar. Die Folgen lagen nach Einschätzung des Botschafters auf der Hand: "Le frein qui, jusqu'à présent, pouvait le mieux contrebalancer les tendances d'une politique purement et spécifiquement nationale-socialiste perd considérablement de sa puissance ${ }^{4}$.

Dem Botschafter schienen die gemäßigten Militärs, Diplomaten und Politiker den radikalen Nationalsozialisten schon seit der Remilitarisierung des Rheinlandes unterlegen ${ }^{5}$. Einen Einflußverlust des Auswärtigen Amtes hatte der Botschafter schon im Herbst 1935 bei dem Gömbös-Besuch notiert ${ }^{6}$. Reichsaußenminister von Neurath verflüchtige sich und kapituliere. $\gg$ La politique extérieure du Reich «, hielt André François-Poncet fest, »est dirigée par le Chancelier, par M. Goering, par M. von Ribbentrop, par M. Hess, par M. Goebbels, par tout le monde, sauf par lui ${ }^{7}$. Nach und nach verlor der Außenminister in den Augen des Botschafters seine Kompetenz. "Le baron de Neurath ne comprend pas toujours le sens des questions qui lui sont posées. Il n'en saisit pas, du premier coup, la portée, ni les répercussions. Et quand il s'apercoit qu'il s'est trompé et qu'il peut en résulter pour lui quelque dommage, il n'hésite jamais à se déjuger et à s'infliger à lui-même un démenti ${ }^{8}$. Vor diesem Hintergrund ist nicht verwunderlich, daß der französische Botschafter die »Beförderung « des deutschen Außenministers zunächst nicht bedauerte. Im Rücktritt Schachts Ende November 1937 sah er dagegen ein »alarmierendes Zeichen «". Der Reichsbankpräsident sei nicht nur ein Gegner der Wirtschaftspolitik, des 4-Jahres-Planes und seines Beauftragten Hermann Göring, sondern auch der Außenpolitik gewesen. »Il est partisan d'un accord avec les puissances occidentales ${ }^{10}$. Seine Ratschläge wurden aber nicht

Ibid.

Ibid. S. 1.

5 Depesche Nr. 160 vom 9. Februar 1938 (Botschafter François-Poncet an Außenminister Delbos), in: DDF VIII/2, Nr. 132, S. 263-269, hier S. 265.

6 Depesche Nr. 1415 vom 2. Oktober 1935 (Botschafter François-Poncet an Ministerpräsident und AuBenminister Laval), in: DDF XII/1, Nr. 310, S. 435-443, hier S. 440.

7 Ibid.

8 Depesche Nr. 815 vom 13. Mai 1936 (Botschafter François-Poncet an Außenminister Flandin), S. 3, in: CADN, Ambassde Berlin, Série B, Carton 205.

9 Telegramm Nr. 4747-4756 vom 27. November 1937, in: DDF VII/2, Nr. 278, S. $498 \mathrm{f}$.

${ }^{10}$ Ibid. 
befolgt, seine Vorschläge nicht gehört. Ende Januar 1938 kursierten dann in Berlin Geriichte, daß die Reichsführung ihren Einfluß auf bzw. in Unternehmen verstärken wolle, daß eine Kabinettsumbildung, ja sogar ein monarchistisches Komplott vorbereitet werde ${ }^{11}$. Diese Gerüchte wurden zwar Anfang Februar dementiert, André François-Poncet glaubte indes, daß sie ein Fünkchen Wahrheit enthielten ${ }^{12}$. Vor allem die Heirat des Feldmarschalls von Blomberg schien dem Botschafter Anlaß »d'un conflit de plus grande ampleur entre le commandement de l'armée et le parti national-socialiste« geworden zu $\operatorname{sein}^{13}$.

Diesen »verborgenen und chronischen« Konflikt hatte André FrançoisPoncet im Sommer 1937 Außenminister Delbos bestätigt, der um eine Überprüfung eines Geheimberichtes aus Berlin gebeten hatte ${ }^{14}$. Über die »lutte souterraine ${ }^{15}$ zwischen Gemäßigten und Radikalen hatte der - wie gezeigt werden konnte - immer wieder berichtet, insbesondere wenn in den Regierungskreisen um eine Entscheidung gerungen wurde oder sich die ökonomischen Schwierigkeiten innenpolitisch bermerkbar machten, wie im Frühjahr 1937. Viele Zeichen deuteten »un état de sourd malaise « an, berichtete damals André François-Poncet, der in vielerlei Hinsicht an die Zeit vor den »Massakern « vom 30. Juni 1934 erinnerte ${ }^{16}$. Die wirtschaftlichen Schwierigkeiten und die außenpolitische Lage des Reiches hätten nicht nur die Wirtschaftspolitiker um Schacht, sondern auch die Generale, insbesondere Fritsch und Beck, sowie mit einiger Zurückhaltung auch von Neurath in Opposition zu den Nationalsozialisten, insbesondere zu Goebbels und Himmler, gebracht. Die Mesalliance von Blombergs, bei der Hitler und Göring als Trauzeugen fungierten, trieb die schwelende Auseinandersetzung auf eine Entscheidung zu, mit der in den »nächsten Tagen« gerechnet würde, telegrafierte André François-Poncet am 2. Februar 1938 nach Paris ${ }^{17}$.

Tatsächlich löste Reichskanzler Hitler die Krise zwei Tage später mit dem beschriebenen Revirement. André François-Poncet glaubte, daß die Entscheidung auf Druck der Parteichefs und insbesondere von Himmler gefallen sei. "C'est celui-ci qui l'aurait finalement emporté « ${ }^{18}$. Das Oberkommando, das in der deutschen Politik ein Element der »Ausgeglichenheit« und der »Mäßigung« darstellte, habe eine Niederlage erlitten. »S'il devait être mis de côté,

1 Telegramme Nr. 517-523 vom 31. Januar 1938, in: DDF VIII/2, Nr. 76, S. $161 f$.

12 Telegramme Nr. 534-539 vom 1. Februar 1938, in: DDF VIII/2, Nr. 79, S. 168f.

13 Telegramme Nr. 563-569 vom 2. Februar 1938, in: DDF VIII/2, Nr. 87, S. $179 f$.

14 Vgl. die Note vom 17. Juni 1937, in: AMAE, Papiers 1940, Papiers Delbos, Cabinet du Ministre, Vol. 1, S. 225-[265], hier S. 262.

15 Ibid. S. 263.

16 Vgl. Telegramm Nr. 1523 vom 14. April 1937, in: DDF V/2, Nr. 272, S. 422f.

${ }^{17}$ Siehe auch Depesche Nr. 136 vom 3. Februar 1938 (Botschafter François-Poncet an Außenminister Delbos), in: DDF VIIU/2, Nr. 98, S. 195-202.

18 Telegramme Nr. 598-601 vom 4. Februar 1938, in: DDF VIII/2, Nr. 101, S. 205. 
comme l'a été M. Schacht, au profit des milieux les plus radicaux du parti nazi, il y aurait lieu de craindre que l'orientation extérieure de l'Allemagne ne subît le contrecoup « ${ }^{19}$. Die Folgen würden aber nicht nur die Außenpolitik betreffen. »Mais si l'on considère qu'il y avait, jusqu'ici, en Allemagne, quatre éléments de pondération relative, l'industrie, le Dr. Schacht, le HautCommandement et $M$. von Neurath avec sa Wilhelmstrasse, et que ceux-ci pourraient être également mis de côté, on ne sera pas disposé à augurer très favorablement de l'avenir ${ }^{20}$. Die Maßnahmen vom 4 . Februar bewertete André François-Poncet als Ende der innenpolitischen Auseinandersetzung. Die Versetzung von Blombergs und von Fritschs biete dem Reichskanzler die Möglichkeit, das Oberkommando vollständig zu reorganisieren. Die personellen Veränderungen an der Spitze des Auswärtigen Amtes seien von ebenso großer Bedeutung ${ }^{21}$.

Trotz des Sieges der Partei und der Steigerung ihres Einflusses und der daraus wohl folgenden Radikalisierung der deutschen Innen- und Außenpolitik sah der Botschafter keinen Grund, den Kopf zu verlieren. »Il faut attendre les gestes et les paroles qui nous éclaireront sur l'état d'esprit et les intentions du nouveau ministre des Affaires étrangères, $M$. von Ribbentrop ${ }^{22}$. Die abwartende Haltung überrascht aus zwei Gründen: Erstens war der Botschafter so oder so von dem expansiven, ja kriegerischen Charakter der deutschen Außenpolitik überzeugt, und zweitens hatte er den neuernannten Außenminister von Anfang an mißtrauisch beäugt. Infolgedessen erschien ihm - nach viertägiger Bedenkzeit - die Zukunft dann doch »problematisch « und die Aussichten düster. Je mehr Zeit verstrich, desto pessimistischer blickte der Botschafter in die Zukunft. »À l'extérieur, et à l'intérieur, le Reich paraît lancé vers l'aventure. Et il faudrait que M. Hitler dans le discours qu'il prononcera, le 20 février, fût bien conciliant et bien précis dans l'expression de sa volonté pacifique, pour dissiper les orages dont l'horizon paraît chargé «" Vor dem Reichstag zeigte sich »Herr Hitler« weder »konziliant « noch »präzise«. Der Reichskanzler schien dem Botschafter entschlossen, seine außenpolitische Linie beizubehalten, ja in jeder Hinsicht und in jede Richtung zu betonen ${ }^{24}$. Insofern sei der 4. Februar 1938 ein wichtiger Wendepunkt in der nationalsozialistischen Politik:

La politique national-socialiste estime que la situation intemationale et le rapport des forces en présence sont désormais tels qu'elle n'a plus besoin de s'embarrasser d'un luxe de

19 Ibid. S. 206.

20 Ibid. S. 207.

21 Vgl. dazu Telegramm Nr. 615 vom 5. Februar 1938, in: DDF VIII/2, Nr. 105, S. $211-$ 215 .

${ }^{22}$ Telegramme Nr. 655-657 vom 6. Februar 1938, in: DDF VIII/2, Nr. 111, S. 223.

23 Depesche Nr. 184 vom 16. Februar 1938 (Botschafter François-Poncet an Außenminister Delbos), in: DDF VIII/2, Nr. 182, S. 353-364, hier S. 364.

24 Telegramme Nr. 910-920 vom 20. Februar 1938, in: DDF VIII/2, Nr. 216, S. 433-435. 
ménagements. Elle estime que l'Allemagne est en mesure de tenir ce qu'elle regarde comme le langage qui convient à une grande puissance, c'est-à-dire le langage qu'elle tenait avant 1914. À cet égard, les cinq années écoulées représentent, à ses yeux, une période [dépassée], celle des précautions, des transitions et des préparatifs. Maintenant s'ouvre une nouvelle phase, qu'on pourrait appeler celle de l'activisme ou de l'action directe ${ }^{25}$.

Die StoBrichtung der deutschen Außenpolitik war dem Botschafter seit langem klar: Der Anschluß Österreichs und der Status der Sudetendeutschen standen als nächstes auf dem Revisionsprogramm Deutschlands. Wenn die Probleme Mitteleuropas geregelt seien, könnte die Frage der Kolonien aufgeworfen werden $^{26}$. Das sei die Rechnung, die in Berlin aufgemacht werde und die seit langem bekannt und Flandin fast offenbart worden $\operatorname{sei}^{27}$.

$\mathrm{Da}$ der Botschafter das außenpolitische Programm des Reiches so nüchtern umriß und keinen Gegenplan entgegenstellte, hing mit seiner aktuellen Enttäuschung über seine Arbeit zusammen. Wie gesehen, hatte André FrançoisPoncet die Ereignisse von Anfang Februar als Sieg der Partei über die Wehrmacht dargestellt. Der offiziöse »Temps « schrieb aber genau das Gegenteil, wie der Botschafter überrascht feststellte ${ }^{28}$. »ll m'est«, schrieb er dem Generalsekretär des französischen Außenministeriums, Alexis Léger, "pénible de voir, en cette occurrence, le peu de cas qui est fait à Paris de mes communications, et le manque total de confiance en mes facultés que révèle l'attitude du Service de Presse. Je me demande, dans ces conditions, s'il est bien nécessaire que je continue à exercer mes fonctions $\aleph^{29}$. Daß der Botschafter auf seinem Posten blieb, überrascht. Denn die Beschwerde blieb ohne Reaktion. Dies mag auch mit dem beschleunigten Gang der Ereignisse zu tun haben, die im folgenden darzustellen sind. Sie ließen einen Botschafterwechsel kaum zu. Nach dem 4. Februar 1938 erwartete nicht nur André François-Poncet »une politique plus radicale $\aleph^{30}$. Das schien dem Botschafter das bemerkenswerteste und beunruhigendste an Hitlers Erklärung vor dem Reichstag. Sie habe zwar keine neuen Forderungen enthalten, die alten aber »sur un ton plus cassant et plus brutal « vorgetragen wurden:

L'impatience, l'arrogance, la menace imprégnait les phrases du Chancelier, plus que l'amour de la paix. M. Hitler a parlé comme un homme qui estime qu'il n'a plus de ménagements à garder, qui ne veut plus marchander ni envisager des compromis, qui est à la fois sûr de sa force et de la faiblesse de ses adversaires, et qui, prenant la tête des exaltés de son Parti, est résolu à se lancer avec eux dans l'aventure. Il peut y avoir, dans cette attitude, une part de bluff; mais il n'y entre pas que du bluff et même le bluff n'en est probablement pas l'essentiel.

Telegramme Nr. 882-887 vom 18. Februar 1938, in: DDF VIII/2, Nr. 197, S. 399 f.

Telegramme Nr. 927-933 vom 21. Februar 1938, in: DDF VIII/2, Nr. 219, S. 439-441.

Siehe Telegramm Nr. 5034 vom 15. Dezember 1937, in: DDF VII/2, Nr. 351.

Telegramme Nr. 662-667 vom 6. Februar 1938, in: DDF VIII/2, Nr. 113, S. $225 f$.

Schreiben vom 11. Februar 1938, in: CADN, Ambassade Berlin, Série B, Carton 683.

Vgl. Telegramme Nr. 946-98 vom 21. Februar 1938, in: CADN, Ambassade Berlin, Série

B, Carton 158, aus dem alle weitere Zitate sind 


\subsection{Der »Anschluß«:}

»le désir le plus cher au couur du Chancelier«

Der $\gg A n s c h l u ß «$ Österreichs war ein Hauptziel der nationalsozialistischen Außenpolitik ${ }^{31}$. Die französische und auch die italienische wollten das verhindern $^{32}$. »Ni Anschluss, ni Habsbourg«, lautete die Formel der französischen Österreichpolitik ${ }^{33}$. Die hatte Anfang der 30er Jahre, wie gesehen, das deutschösterreichische Zollunionsprojekt - »c'est l'Anschluss économique« - vereitelt. André François-Poncet hatte, wie gezeigt, mit seinem "plan constructif« erheblichen Anteil an diesem Erfolg. Vor diesem Hintergrund ist verständlich, $\mathrm{da} ß$ er als Botschafter der deutschen Österreichpolitik besondere Aufmerksamkeit schenkte, insbesondere nach der Machtïbernahme der Nationalsozialisten, die erklärtermaßen den »Anschluß « Österreichs anstrebten. Der war jedoch unmöglich, solange Rom und Paris Berlin den Weg nach Wien versperrten ${ }^{34}$. "Le parti national-socialiste «, telegrafierte André FrançoisPoncet im März 1933 nach Paris, »ne voit pas sans inquiétude se préparer à Rome et à Paris des arrangements qui auraient pour conséquence de stabiliser la situation actuelle, d'assurer la continuation de la conférence de désarmement, et de remettre à plus tard la discussion d'une révision éventuelle des frontières $\aleph^{35}$. Dementsprechend groß sei die deutsche Enttäuschung über die italienische Politik. »Cette désillusion ne peut, « schien André FrançoisPoncet, "qu'inciter les dirigeants actuels du Reich à une attitude plus prudente à l'égard de la Société des Nations et des principaux problèmes actuellement en discussion $\aleph^{36}$. Schon vor der Unterzeichnung des 4-Mächte-Paktes glaubte der französische Botschafter Zeichen "d'un changement de tactique« feststellen zu können ${ }^{37}$.

Vgl. Adolf HITLER, Mein Kampf, Bd. 1: Eine Abrechnung, München 1933, S. 1. Zur nationalsozialistischen Österreichpolitik siehe HILDEBRAND, Vergangenes Reich, S. 688ff. und S. 748ff. sowie Norbert SCHAUSBERGER, Österreich und die nationalsozialistische AnschluB-Politik, in: Manfred FUNKE (Hg.), Hitler, Deutschland und die Mächte. Materialien zur Außenpolitik des 3. Reiches, Düsseldorf 1976, S. 728-756.

Siehe Thomas ANGERER, Die französische Österreichpolitik vor dem "AnschluB«1938, in: VZG 40 (1992) S. 29-59.

33 Siehe DDF VI/1, Nr. 285.

34 Über die Anfänge des Ringens um Österreich informiert Marco BERTOLASO, Die erste Runde im Kampf gegen Hitler: Frankreich, Großbritannien und die österreichische Frage 1933/34. Eine Untersuchung der Außenpolitik der Westmächte in den ersten 18 Monaten des »Dritten Reiches « auf der Grundlage diplomatischer Akten, Hamburg 1995.

35 Telegramme Nr. 481-492 vom 21. März 1933, in: DDF III/1, Nr. 23, S. 46-48, hier S. 48. 36 Ibid.

37 Depesche Nr. 516 vom 24. Mai 1933 (Botschafter François-Poncet an Außenminister Paul-Boncour), in: DDF IIU/1, Nr. 317, S. 567-569, hier S. 569. Wenige Tage später verhängte die Reichsregierung einen Zwangsumtausch von 1000 Mark, der den deutschen 
$\mathrm{Da}$ die Nationalsozialisten nicht nur »legale Mittel« zur Realisierung des "österreichischen Traums " Hitlers anwendeten, wurde im Sommer des Jahres 1933 offensichtlich: Deutsche Radiostationen versorgten die Alpenrepublik mit Propagandasendungen und deutsche Flugzeuge warfen über den Großstädten Flugblätter ab. Angesichts der »activité subversive« Deutschlands in Österreich entschloß sich Großbritannien zu einem diplomatischen Schritt, dem sich Frankreich und Italien anschlossen ${ }^{38}$. Die trilaterale Demarche verlor nach Ansicht des Botschafters durch das Vorpreschen Italiens und der öffentlichen Vorankündigung durch die Medien $^{39}$ erheblich an Gewicht, so $\mathrm{da} ß$ André François-Poncet noch den Artikel 11 der Konvention und den Artikel 80 des Versailler Vertrages ins Spiel bringen wollte. "L'étalage devant la Société des Nations de toute la série des actes dont l'Autriche a été victime est une perspective qui ne saurait être agréable à l'Allemagne ${ }^{40}$. Schließlich gab sich der Botschafter mit der Demarche zufrieden. "Le régime hitlérien est plus susceptible que tout autre«, begründete er seinen Meinungswechsel, »à cause même des campagnes qu'il a dirigées contre d'autres régimes. Il est obligé de donner l'impression à l'Allemagne, qu'en tout ce qui touche au prestige et à la dignité nationale, il est résolu à n'accepter aucune diminution. Il s'est condamné lui-même à une sorte de vantardise ou de bluff permanent ${ }^{41}$. Wie diese Politik enden würde, hinge vor allem von der Haltung Italiens und Großbritanniens, aber auch von den Wünschen Österreichs ab. André François-Poncet betonte:

Ce qu'il y a de sûr c'est que les indulgences et les concessions n'ont pas, jusqu'à présent, adouci l'humeur des Nazis; c'est que leur prétention de gagner l'Europe à leur mouvement s'affiche avec une audace grandissante; c'est que l'activité des cellules qu'ils créent et qu'ils subventionnent dans tous les pays limitrophes, Roumanie, Hongrie, Russie, Suède, Danemark, Hollande, s'accentue; c'est que l'empoisonnement de l'esprit public, l'excitation militariste et chauvine qu'ils propagent méthodiquement s'emparent des masses avec une rapidité inquiétante, c'est, enfin, que, s'il est possible d'arrêter ou de ralentir ces progrès les Puissances intéressées au maintien de la paix et de la liberté en Europe ont le devoir de s'y employer ${ }^{42}$.

Österreichtourismus unterbinden sollte, siehe Telegramme Nr. 997-1000 vom 27. Mai 1933, in: DDF III/1, Nr. 323, S. 581.

38 Vgl. Telegramme Nr. 1229-1230 vom 4. August 1933, in: DDF IV/1, Nr. 82, S. 154f.; Telegramme Nr. 1402-1404 vom 5. August 1933, in: DDF IV/1, Nr. 86, S. 160f. und Telegramme Nr. 1410-1420 vom 7. August 1933, in: DDF IV/1, Nr. 90, S. 165-168.

39 André François-Poncet kritisierte diese Indiskretionen wiederholt z. B. in Depesche Nr. 870 vom 9. August 1933 (Botschafter François-Poncet an AuBenminister PaulBoncour), S. 2, in: CADN, Ambassade Berlin, Série B, Carton 195.

${ }^{40}$ Telegramme Nr. 1421-1424 vom 8. August 1933, in: DDF IV/1, Nr. 95, S. 171f.

${ }^{41}$ Depesche Nr. 870 vom 9. August 1933 (Botschafter François-Poncet an AuBenminister Paul-Boncour), S. 7, in: CADN, Ambassade Berlin, Série B, Carton 195.

42 Ibid. S. 12. 
Das war der Punkt, auf den der Botschafter immer wieder kam. Die interessierten Mächte hätten die Pflicht, sich mit den Auswirkungen des Nationalsozialismus zu beschäftigen. Und da »Nachgiebigkeit« und »Konzessionsbereitschaft « die Nationalsozialisten nicht befrieden könnten, müsse man sich, so der logische Schluß aus der Überlegung, unnachgiebig zeigen. André François-Poncet war, wie gesehen, insbesondere nach dem deutschen Austritt aus dem Völkerbund für diese Politik, die dann unter Außenminister Barthou ein Jahr die französische Deutschlandpolitik bestimmte.

Vor diesem Hintergrund ist verständlich, daß sich Anfang Dezember 1933 »Herr Hitler « entschlossen habe, den Realitäten Rechnung zu tragen und hinsichtlich Österreichs auf die deutsche Anziehungskraft zu setzen. »Il s'est donc convaincu de la nécessité de savoir résister aux tentations de l'amourpropre comme aux impulsions de l'enthousiasme, et de pratiquer l'art d'attendre, de louvoyer et de procéder par étapes « ${ }^{43}$. Die nächste Etappe war schon im Februar 1934 erreicht: Deutschland bekämpfte mit allen Mitteln Bundeskanzler Dollfuß. André François-Poncet wollte die deutsche Österreichpolitik wieder im Völkerbundsrat verhandeln lassen, weil das Deutschland unangenehm wäre. Ernsthafter seien für Deutschland aber Meinungsverschiedenheiten mit Italien, die das Reich zu vermeiden versuchen würde ${ }^{44}$. Großbritannien und Frankreich konnten Italien erneut zu einer gemeinsamen Erklärung zur Unabhängigkeit Österreichs gewinnen, die in Berlin Überraschung und Verwirrung auslöste, weil die Reichsführung eine Einigung der drei Mächte für unmöglich hielt ${ }^{45}$.

André François-Poncet wiederholte in diesem Zusammenhang indirekt die Maxime seiner Deutschlandpolitik: Die Politik des Reiches sei, so die Grundüberzeugung des Botschafters, nur durch eine Mächtegruppe beeinflußbar. Insofern müsse sich Frankreich mit Großbritannien im Bunde wissen, der von Fall zu Fall - erweitert werden müsse. Im Falle Österreichs schien André François-Poncet Italien die notwendige Ergänzung. Denn: »La lutte dont l'Autriche doit être le prix apparaît, avant tout, à l'heure actuelle, comme un duel entre l'influence allemande et l'influence italienne, entre le nationalsocialisme et le fascisme, entre Hitler et Mussolini. C'est sur le terrain de la politique autrichienne que vont s'affronter les deux adversaires ${ }^{46}$. Da die Staaten der Kleinen Entente den "Anschluß « weniger fürchteten als die Restauration, setzte André François-Poncet vor allem auf die britisch-franzö-

43 Depesche Nr. 1327 vom 6. Dezember 1933 (Botschafter François-Poncet an Außenminister Paul-Boncour), in: DDF V/1, Nr. 91, S. 177-179, hier S. 177.

44 Depesche Nr. 180 vom 7. Februar 1934 (Botschafter François-Poncet an Ministerpräsident und Außenminister Daladier), S. 4f., in: CADN, Ambassade Berlin, Série B, Carton 196/1.

45 Depesche Nr. 245 vom 21. Februar 1934 (Botschafter François-Poncet an Außenminister Barthou), in: DDF V/1, Nr. 415, S. 779-782.

46 Ibid. S. 782. 
sische Entente: »Et plus clairement que jamais, « machte der Botschafter Ende Februar 1934 seine Position klar, »il apparaît que, seule, une entente francobritannique pourra faire régner dans le bassin du Danube un ordre conforme aux intérêts de ses propres habitants et à ceux de la paix européenne et non pas dicté par des ambitions ou des appétits égoïstes « ${ }^{47}$.

$\mathrm{Da} \beta$ die von ihm geforderte Allianzpolitik »une impression profonde « auf die Reichsregierung gemacht zu haben schien, konnte André François-Poncet zwei Wochen später Paris vor Augen führen ${ }^{48}$. Der Besuch des österreichischen und des ungarischen Regierungschefs in Rom hatte zu einer neuen Einschätzung geführt ${ }^{49}$. Daß sich Deutschland mit Polen konsultiere, sich Österreich und Ungarn aber vor den italienischen Wagen spannen lasse, schien Deutschland eine Lehre zu $\operatorname{sein}^{50}$. Eine zurückhaltendere Haltung wurde nicht nur gegenüber Österreich eingenommen, sondern - wie gesehen - auch in der Abrüstungsfrage und gegenüber Italien. Trotz des scheinbaren Politikwechsels in Berlin warnte der Botschafter vor der deutschen Außenpolitik. »Si elle rectifie son cours et apprend à se servir d'armes plus raffinées, la diplomatie hitlérienne n'a donc pas, pour autant, renoncé à l'action et il ne saurait nous échapper que moins cette action sera brutale, plus elle sera périlleuse pour nous $\aleph^{51}$. Daß hinter der Fassade der Diplomatie intensive Aktionen vorbereitet wurden, war dem Botschafter schon Mitte April $\mathrm{klar}^{52}$. Sie wurden mit dem Putsch der österreichischen Nationalsozialisten und der Ermordung Bundeskanzler Dollfuß' Ende Juli 1934 offensichtlich $^{53}$. Trotz dieser Eskalation ließ sich André François-Poncet schnell wieder beruhigen. Die Entsendung Franz von Papens als Sonderbotschafter nach Wien und die Absetzung Habichts schienen ihm den Wunsch zu belegen »de renoncer aux méthodes de violence et de chercher désormais dans la souplesse, c'est-à-dire dans la ruse, la solution du problème austro-allemand ${ }^{54}$. André François-Poncet rief in diesem Zusammenhang in Erinnerung, daß von Papen den Nationalsozialismus in die deutsche Regierung eingeführt habe. Soltte er das in Österreich wiederholen? Botschafter von Papen brachte im Sommer 1935 zunächst mal einen deutsch-österreichischen Vertrag ins Gespräch, der die österreichische

Depesche Nr. 285 vom 28. Februar 1934 (Botschafter François-Poncet an Außenminister Barthou), in: DDF V/1, Nr. 448, S. 840-842, hier S. 842. »Plutôt l'Anschluss que Habsbourg « war die außenpolitische Maxime dieser Staaten, vgl. DDF VI/1, Nr. 285. Depesche Nr. 372 vom 15. März 1934 (Botschafter François-Poncet an Außenminister Barthou), in: DDF VI/1, Nr. 10, S. 23-27, hier S. $23 f$.

49 Ibid.

50 Ibid. S. 24.

51 Ibid. S. 27.

52 Vgl. Depesche Nr. 570 vom 18. April 1934 (Botschafter François-Poncet an Außenminister Barthou), in: DDF VV1, Nr. 111, S. 290-294.

${ }^{53}$ Zur Entwicklung siehe HILDEBRAND, Vergangenes Reich, S. $690 f$.

${ }^{54}$ Telegramme Nr. 1446-1449 vom 27. Juli 1934, in: DDF VII/1, Nr. 2, S. 3-5, hier S. 4. 
Unabhängigkeit auf zehn Jahre garantieren sollte ${ }^{55}$. Voraussetzung war, daß die Pressekampagne aufhöre, die Emigranten zurückkehren könnten und ein "nationaler « Politiker ins Wiener Kabinett aufgenommen werden würde. Dann akzeptiere Deutschland auch das Verbot der NSDAP in Österreich und biete erhebliche wirtschaftliche Zugeständnisse, vor allem im Tourismus, an. Die Gespräche zogen sich hin ${ }^{56}$. Sie wurden Ende Mai 1936 von dem Rücktritt Starhembergs aus der Regierung gestört, der André François-Poncet gefährlich erschien. »Ce demier incident mérite de retenir l'attention, car il fournit une sérieuse raison de soupçonner que, faute de voir éclater les troubles sur lesquels il spécule, le Troisième Reich n'hésiterait pas à les provoquer lui-même en recourant, au besoin, à des agents provocateurs ${ }^{57}$. Die Reichsregierung schickte aber keine Provokateure, sondern Unterhändler, die am 11. Juli 1936 einen Vertrag mit Österreich schlossen. André François-Poncet zweifelte sofort am Wert dieser Abmachung: »Et quand on songe aux arrière-pensées que le III ${ }^{\mathfrak{e}}$ Reich nourrit contre la Tchécoslovaquie et dont la première étape de réalisation doit être marquée par l'établissement à Vienne d'un gouvernement docile, il est permis de douter que l'accord austro-allemand du 11 juillet ait vraiment consolidé pour longtemps la paix de l'Europe “" ${ }^{58}$. André FrançoisPoncet fürchtete, daß die Reichsregierung langsam, aber sicher einen zentraleuropäischen Block unter ihrer Führung schmieden möchte ${ }^{59}$. »J'ai, en effet, l'impression que l'opération sur la Tchécoslovaquie, prévue dès le lendemain de l'accord austro-allemand, vient de commencer « ${ }^{60}$. Diese Operation müsse im Zusammenhang mit den Anstrengungen gesehen werden, die Deutschland gegenüber Litauen und den baltischen Staaten unternehme. »Le Reich semble, à l'heure actuelle, préoccupé d'achever de régler sur une base pacifique et bilatérale ses relations avec ses voisins de l'est et du sud-est, Autriche, Tchécoslovaquie, Pologne, États baltes ${ }^{61}$. Die deutsche Außenpolitik hielt sich aber - wie gesehen - vor dem Hintergrund des Spanischen Bürgerkrieges weiter zurück. Die Lage veränderte sich erst mit der An-

55 Telegramme Nr. 2201-2202 vom 23. August 1935, in: DDF XII/1, Nr. 18, S. 28.

56 Voraussetzungen für den umfassenderen »Unabhängigkeitsvertrag « sein sollte. Siehe Telegramme Nr. 2234-2236 vom 28. August 1935, in: DDF XIV/1, Nr. 60, S. 87f. André François-Poncet hatte nach einem Treffen mit Franz von Papen im Herbst 1935 den Eindruck, daß die Gespräche fortgesetzt werden würden, vgl. Telegramm Nr. 2576 vom 7. Oktober 1935, in: DDF XII/1, Nr. 372, S. 533-535.

57 Depesche Nr. 908 vom 28. Mai 1936 (Botschafter François-Poncet an Außenminister Flandin), S. 7, in: CADN, Ambassade Berlin, Série B, Carton 205.

58 Telegramme Nr. 2137-2145 vom 12. Juli 1936, in: DDF II/2, Nr. 432, S. 663-665.

${ }^{59}$ Depesche Nr. 1202 vom 22. Juli 1936 (Botschafter François-Poncet an Außenminister Delbos), S. 11, in: CADN, Ambassade Berlin, Série B, Carton 206.

60 Telegramme Nr. 2607-2608 vom 18. August 1936, in: DDF IIL/2, Nr. 167, S. 240.

61 Ibid. S. 241. 
näherung Italiens an Deutschland grundlegend. Die deutsch-italienische Zusammenarbeit habe zwar, so der Botschafter Mitte Oktober 1936, nach der Auflösung der Heimwehren noch immer einen »empirischen Charakter«, sei aber nicht weniger gefährlich ${ }^{62}$. Gleichwohl hielten sich die Nationalsozialisten im Herbst und Winter 1936 in Österreich zurück, so daß André François-Poncet keinen Anlaß sah, die deutsche Österreichpolitik anzuprangern. Und das, obwohl sich die »Achse« verfestigt hatte. Erst im Frühjahr 1937 drohten sich die Beziehungen zu Österreich wieder anzuspannen, weil die Reichsregierung von den Ergebnissen des im Sommer 1936 geschlossenen Juli-Abkommens enttäuscht und von der »energischen und entschlossenen « Haltung des Bundeskabinetts unter Schuschnigg überrascht war ${ }^{63}$. Angesichts der Situation und den laufenden Verhandlungen wartete die Reichsregierung aber weiter ab. Erst der Besuch des italienischen Ministerpräsidenten in Berlin setzte die Österreich-Frage wieder auf die Tagesordnung ${ }^{64}$.

Deutschland verfolgte ja in Österreich nach wie vor das gleiche Ziel - den "Anschluß«. Dem schien Deutschland nach den deutsch-italienischen Gesprächen einen Schritt näher gekommen, da Mussolini wohl hat anerkennen müssen, daß das Juli-Abkommen keine zufriedenstellende Lösung für Deutschland darstelle. Das weitere Vorgehen sei zwar nicht festgelegt worden, André François-Poncet war sich aber sicher, daß Mussolini seine schützende Hand von Österreich genommen habe ${ }^{65}$. Deutschland hielt sich gleichwohl noch zurück; konkrete Schritte wurden zunächst nicht unternommen. Erst nach der Blomberg-Fritsch-Krise schien André François-Poncet wieder einmal die Zeit für den »Anschluß« gekommen zu sein. Das Berchtesgadener Treffen zwischen Hitler und Schuschnigg am 12. Februar 1938 hielt der Botschafter anfänglich für »une sorte d'ultime tentative de conciliation $\aleph^{66}$. André François-Poncet glaubte, daß mit diesem Abkommen der »Anschluß« vermieden werden könne. „Ce que le Reich poursuit pour l'instant«, telegrafierte er am 16. Februar nach Paris, »semble être plutôt l'Angleichung, la mise au pas, la synchronisation, comme s'il voulait faire peu à peu de l'Autriche une sorte de Außenminister Delbos), in: DDF II/2, Nr. 345, S. 516-519, hier S. 519.

63 Vgl. Depesche Nr. 236 vom 18. Februar 1937 (Botschafter François-Poncet an Außenminister Delbos), in: DDF IV/2, Nr. 464, S. 803-807 und Depesche Nr. 488 vom 25. März 1937, in: DDF V/2, Nr. 180, S. 287-291, insbesondere S. 291. Zum Hintergrund siehe HILDEBRAND, Vergangenes Reich, S. 727f. und Thomas ANGERER, Erster Schritt zum AnschluB? Frankreich und das Juli-Abkommen, in: GG 7 (1988) S. 185-194. Vgl. Depesche Nr. 1487 vom 23. September 1937 (Botschafter François-Poncet an Außenminister Delbos) [S. 1], in: CADN, Ambassade Berlin, Série B, Carton 209.

66 Telegramme Nr. 830-835 vom 16. Februar 1938, in: DDF VIII/2, Nr. 170, S. $334 f$. 
territoire de Dantzig élargi « ${ }^{67}$. Die französische Regierung forderte ihren Botschafter gleichzeitig auf, mit seinem britischen Kollegen beim Auswärtigen Amt vorzusprechen ${ }^{68}$. Nevile Henderson sprach indes - mangels Instruktionen - ohne André François-Poncet bei Joachim von Ribbentrop vor. Die deutsche Antwort ließ ebensowenig Gutes für die Zukunft ahnen wie die bevorstehende Reichstagsrede Hitlers ${ }^{69}$. Tatsächlich zeigte sich der Reichskanzler in den außenpolitischen Passagen seiner Rede entschlossen, »non seulement à ne pas s'écarter de sa ligne de conduite antérieure, mais à accentuer, au contraire, son attitude dans toutes les directions qu'il a suivies jusqu' ici ${ }^{70}$. Die härtere Gangart in der Außenpolitik verhieß für Österreich keine rosige Zukunft. Zumal Reichsmarschall Göring dem Botschafter in aller Offenheit erklärte, daß sie zwar die Unabhängigkeit Österreichs im Moment respektierten, diese Unabhängigkeit aber ein Ende nehmen werde und Österreich an Deutschland angeschlossen werde ${ }^{71}$. Infolgedessen erschien André François-Poncet das Berchtesgadener Abkommen in einem anderen Licht: "L'accord de Berchtesgaden est pour elle une étape. Cette étape sera très rapidement franchie; car le cabinet autrichien sera bientôt submergé. Après quoi, viendra, soit directement, soit par le détour d'un plébiscite, l'heure du rattachement ${ }^{72}$. Der Botschafter glaubte, daß sich der österreichische Bundeskanzler Illusionen mache ${ }^{73}$. Der machte indes in einer außerordentlichen Bundesratssitzung deutlich, daß mit dem Abkommen vom 12. Februar die Grenze erreicht sei. Diese beschränkte die deutschen Wünsche, die gerade nach dem Wechsel von Eden zu Halifax im Foreign Office erfüllbar schienen $^{74}$. Entgegen dem deutschen Kalkül verhandelte die britische Regierung aber mit der französischen über eine weitere Demarche zugunsten Österreichs. André François-Poncet warnte indes, daß dieser Schritt zwar erfolgreich sein könne, aber auch das Risiko berge, einen »allgemeinen Aufruhr« auszulösen. Insofern müsse die britische Unterstützung sicher sein. Denn: »Une

Telegramme Nr. 851-852 vom 16. Februar 1938, in: DDF VIII/2, Nr. 175, S. 339f., hier S. 339. Siehe auch das Resümee in Depesche Nr. 183 vom 16. Februar 1938 (Botschafter François-Poncet an Außenminister Delbos), in: DDF VIII/2, Nr. 181, S. 347-353. Siehe die Instruktionen im Telegramm Nr. 174 vom 16. Februar 1938, in: DDF VIII/2, Nr. 169, S. 333.

${ }^{69}$ Zum einseitigen Vorgehen Nevile Hendersons siehe Telegramme Nr. 859-860 vom 17. Februar 1938, in: DDF VIII/2, Nr. 185, S. 379f. Die deutsche Reaktion auf die Demarche in den Telegrammen Nr. 866-872 vom 17. Februar 1938, in: DDF VIIU/2, Nr. 189 , S. 383f. und in den Telegrammen Nr. 882-887 vom 18. Februar 1938, in: DDF VIII/2, Nr. 197, S. 399f.

70 Siehe die erste Analyse der Reichtagsrede vom 20. Februar in den Telegrammen Nr. 910920 vom 20. Februar 1938, in: DDF VIII/2, Nr. 216, S. 433-435, hier S. 434.

71 Telegramme Nr. 927-933 vom 21. Februar 1938, in: DDF VIII/2, Nr. 219, S. 439f.

72 Ibid.

73 Telegramm Nr. 985 vom 24. Februar 1938, in: DDF VIIU/2, Nr. 261, S. $518 f$.

74 Telegramme Nr. 936-938 vom 21. Februar 1938, in: DDF VIII/2, Nr. 220, S. 441. 
déclaration énergique, si elle devait être suivie d'une reculade, aurait, dans les circonstances présentes, un effet désastreux ${ }^{75}$. Der Botschafter fürchtete, daß die »günstigen« Rahmenbedingungen die "Dreistigkeit« der Nationalsozialisten steigern werde ${ }^{76}$. Das Abkommen vom 12. Februar erschien ihm vor diesem Hintergrund nur noch als $»$ Waffenstillstand $" 77$. Nach der Linzer Rede Schuschniggs und der Ankündigung der Volksabstimmung ${ }^{78}$ verschlechterte sich die Stimmung weiter:

Quoi qu'il en soit, il paraît vraisemblable que, d'ores et déjà, M. Hitler se prépare à riposter à ce qu'il considère comme un défi et il est malheureusement probable que l'affaire autrichienne, loin de trouver dans le plébiscite de dimanche prochain un dénouement pacifique, connaîtra de nouvelles difficultés et sera exposée à de dramatiques rebondissements ${ }^{79}$.

Die ließen bekanntlich nicht lange auf sich warten ${ }^{80}$. Die Ereignisse, die zum deutschen Einmarsch in die Alpenrepublik führten, müssen an dieser Stelle nicht dargestellt werden, weil sie der Botschafter in Berlin weder notierte, noch reflektierte. Er blieb unbeteiligt an der Entwicklung. Erst in der Nacht vom 11. auf den 12. März griff André François-Poncet in den Gang der Ereignisse ein, als ihn seine Regierung beauftragte, sich der Demarche seines britischen Kollegen anzuschließen ${ }^{81}$. Die "plus graves réactions « blieben indes nicht nur bei den betroffenen Regierungen, sondern auch bei André FrançoisPoncet aus: "Que l'Allemagne ait adopté tout de suite les solutions les plus radicales et proclamé sans attendre le rattachement de l'Autriche n'étonnera pas ceux qui connaissent la mentalité et les procédés des nazis. Ce sont des hommes qui, dans l'action, ne s'arrêtent que lorsqu'ils se heurtent à un

75 Telegramme Nr. 1011-1012 vom 26. Februar 1938, in: DDF VIII/2, Nr. 278, S. 552. André François-Poncet erinnerte an sein Gespräch mit Göring, siehe Telegramme Nr. 189 und 219 vom 17. und 21. Februar. Anfang März befürchtete man in Berlin »bientôt une tournure dramatique « in Österreich, vgl. Telegramme Nr. 1053-1054 vom 1. März 1938, in: DDF VIIU/2, Nr. 288, S. 567f. Optimistisch blieben die Österreicher in Berlin, vgl. Telegramm Nr. 1078 vom 3. März 1938, in: DDF VIII/2, Nr. 306, S. 596.

76 Depesche Nr. 238 vom 3. März 1938 (Botschafter François-Poncet an AuBenminister Delbos), in: DDF VIII/2, Nr. 308, S. 598-603, hier S.603.

77 Ibid. S. 598.

78 Schulthess' Europäischer Geschichtskalender 1938, S. 218

79 Vgl. Depesche Nr. 260 vom 9. März 1938 (Botschafter François-Poncet an AuBenminister Delbos), in: DDF VIII/2, Nr. 350, S. 677-682, hier S. $681 \mathrm{f}$.

$80 \mathrm{Zu}$ der erwarteten Haltung Deutschlands siehe Telegramme Nr. 1191-1193 vom 10. März 1938, in: DDF VIIL/2, Nr. 359, S. 702f. André François-Poncet gab am 11. März Informationen eines Kollegen weiter, der drei Militärkolonnen in Richtung Freilassing, Füssen und Kufstein beobachtet hatte, vgl. Telegramme Nr. 1206-1207 vom 11. März 1938, in: DDF VIII/2, Nr. 365, S. 718.

81 Telegramm Nr. 324 des französischen Außenministers Delbos an den Botschafter François-Poncet vom 11. März 1938, in: DDF VIII/2, Nr. 375, S. 724f. Text der um 23 Uhr übergebenen Protestnote im Telegramm Nr. 1220 vom 12. März 1938, in: DDF VIII/2, Nr. 384, S. 733f. Die deutsche Antwort im Telegramm ohne Nummer vom 12. Mărz 1938, in: DDF VIII/2, Nr. 397, S. 746-748. 
obstacle plus fort qu'eux « ${ }^{82}$. André François-Poncets bemängelt damit indirekt, daß den Nationalsozialisten kein Hindernis in den Weg gelegt wurde. Seit dem März 1936 sei der »Anschluß« vorhersehbar gewesen. Die Remilitarisierung des Rheinlandes war demnach der Ausgangspunkt für den »Anschluß $\ll^{83}$. Daß Frankreich den Bruch des Vertrages von Locarno hingenommen habe, weil Großbritannien in der Vertragsverletzung keinen casus belli sehen wollte, habe Deutschland überzeugt, daß Frankreich und Großbritannien für Österreich schon gar nicht zu den Waffen greifen werde. Frankreich hätte also im März 1936 zu den Waffen greifen müssen, so der indirekte Vorwurf des Botschafters, um die Ereignisse vom März 1938 zu verhindern. Das wäre, rückblickend, die richtige Reaktion gewesen. André François-Poncet selbst hatte zu der Zeit - wie gesehen - zunächst nur den Abzug des Botschafters gefordert. Ihm war im März 1936 bewußt, daß die Regierung Sarraut wenige Wochen vor den Parlamentswahlen keinen Krieg gegen Deutschland erklären konnte. André François-Poncet plädierte zwar anschließend für eine scharfe Reaktion bzw. harte Haltung, schwenkte aber bald wieder auf die Verhandlungslinie ein.

Insofern fällt der gegen die französischen Regierungen erhobene Vorwurf auf ihn zurück. Der Botschafter legte Deutschland ebensowenig wie diese »Hindernisse« in den Weg. Daß der zum »Anschluß« Österreichs führe, hatte André François-Poncet immer wieder und seit Ende 1937 verstärkt vorhergesagt. Paris schenkte den Warnungen aus Berlin aber kein Gehör. Die Enttäuschung André François-Poncets darüber mag die relative Gleichgültigkeit des Botschafters vor und nach dem "Anschluß« erklären. Wie dem auch gewesen sein mag, André François-Poncet war sich sicher, daß die Tschechoslowakei das nächste Opfer Deutschlands werden würde. Daß sich das "Dritte Reich « zurückhalten könne, glaubte der Botschafter nicht. Der »hitlérisme pangermaniste « habe "uni au fascisme « die Beherrschung Europas im Blick. Wer dem Widerstehen wolle, müsse die Tschechoslowakei halten. Eine politische und militärische Aufgabe, der wir uns im letzten Kapitel zuwenden wollen.

82 Telegramm Nr. 1252 vom 14. März 1938, in: DDF VIII/2, Nr. 428, S. 782 f.

${ }^{83}$ Depesche Nr. 273 vom 14. März 1938 (Botschafter François-Poncet an Außenminister Paul-Boncour), in: DDF VIIU/2, Nr. 433, S. 789-803, hier S. 798f. 


\subsection{München: »un dernier effort«}

Nach dem »Anschluß « Österreichs schien André François-Poncet die Zukunft besorgniserregend. »Dès maintenant«, schrieb er Ende März nach Paris, »il apparaît clairement qu'aux yeux des dirigeants du Reich - et d'une grande partie de l'opinion exaltée par la création de la Grande Allemagne - la conquête de l'Autriche n'est pas un terme, mais une étape « ${ }^{84}$. Die nächste Etappe, so die Erwartung des französischen Botschafters, würde Deutschland in die Tschechoslowakei führen. »Il n'est pas douteux qu'ils ne soient, dès maintenant, décidés à obtenir, dans un délai plus ou moins long et d'une façon ou de l'autre, la solution du problème sudète ${ }^{85}$. Daß die Sudetenfrage auf der Tagesordnung stand, hatte André François-Poncet - wie gesehen - sofort nach dem »Anschluß« gemeldet. Deutschland werde versuchen, den errungenen Erfolg und den gewonnenen Eindruck gegenüber den kleineren Staaten auszunutzen. Vor diesem Hintergrund schien dem Botschafter allein eine britischfranzösische Union und Aktion eine "vernünftige« Lösung des Problems der sudetendeutschen Minderheit in der Tschechoslowakei herbeiführen zu können $^{86}$. Die britisch-französische Entente war ein Element der Doppelstrategie, die der Botschafter gegen die deutsche Tschechoslowakei-Politik entwikkelte $^{87}$. Das zweite sollte die tschechoslowakische Regierung beisteuern, indem sie sich gegenüber den (sudeten)deutschen Forderungen aufgeschlossen zeige. André François-Poncet erwartete nämlich vorerst keine »opération soudaine« Deutschlands. »Je ne pense pas«, bekräftigte der Botschafter seine Einschätzung, »qu'il y ait lieu de craindre une agression immédiate ${ }^{88}$. Denn eine militärische Operation gegen die Tschechoslowakei bedürfe der Vorbereitung, die noch nicht festgestellt werden könnte ${ }^{89}$. Außerdem sei sich die Reichsführung nicht sicher, daß sie - »malgré les flottements de l'Angleterre et les embarras de la France « - nicht eine "guerre générale" auslösen werde. »Il en accepte, sans doute, l'éventualité; mais il n'est pas probable qu'il veuille, dès aujourd'hui, en provoquer, lui-même, le risque;

84

88

S. 888. Siehe auch Depesche Nr. 295 vom 22. März 1938 (Botschafter François-Poncet an AuBenminister Paul-Boncour), in: DDF IX/2, Nr. 21, S. 31.

89 Telegramm Nr. 1287 vom 17. März 1938, in: DDF VII/2, Nr. 476, S. 887-889, hier S. 888. 
>l'affaire〈, selon lui, n'est pas encore >mûre «" ${ }^{90}$. Allerdings rechneten die Nationalsozialisten mit »unvermeidlichen Konzessionen« der Tschechoslowakei. »Ces concessions signifient, pour l'essentiel, l'octroi aux Allemands des Sudètes d'un statut spécial, comportant une administration allemande, des écoles allemandes, une police allemande, etc. et faisant, désormais, de la Tchécoslovaquie, un état >sudéto-tchécoslovaque «"1. Diese »Reformen« blieben der Regierung in Prag überlassen, die aber durchaus Gegenstand eines Arrangements analog zum deutsch-österreichischen Juliabkommen werden könnten ${ }^{92}$.

Die deutschlandpolitischen Vorstellungen des französischen Botschafters sahen also in der sudetendeutschen Frage eine Doppelstrategie vor, die - wie immer - auf einer engen Zusammenarbeit Frankreichs und Großbritanniens basierte und die mit einer nachgiebigen Tschechoslowakei rechnete. So hoffte André François-Poncet den Radikalen in der deutschen Führung den Wind aus den Segeln zu nehmen und den Gemäßigten in die Hände zu spielen. Während sich jene außer dem Anschluß der Sudeten und der Auflösung der Tschechoslowakei keine ernsthafte Lösung vorstellen konnten, schienen sich diese mit einer Umwandlung der Tschechoslowakei in eine Art Bundesstaat nach Schweizer Vorbild zufriedengeben zu können. »Pour le moment«, telegrafierte André François-Poncet Ende März 1938 nach Paris, »il semble que les dirigeants du Reich, et $\mathbf{M}$. Hitler lui-même, soient plus près de la seconde que de la première, qu'ils n'envisagent pas, en tout cas, de recourir à la violence, avant d'avoir tenté les voies de la conciliation ${ }^{93}$. Entscheidend sei, ob die Sudetendeutschen innerhalb einer vernünftigen Frist ein zufriedenstellendes Statut bekämen. "Mais ce que les Allemands jugeraient satisfaisant sera-t-il jugé possible par les Tchèques? «94. Das war die Gretchenfrage. Die Antwort der Reichsregierung werde, so der Botschafter, von deren Einschätzung der politischen Lage in Europa und dem militärischen Kräfteverhältnis abhängen. Vor diesem Hintergrund bedauerte André François-Poncet die Haltung der britischen Regierung, die nicht eindeutig Position für die Tschechoslowakei beziehen wollte, um Deutschland im unklaren über ihre Politik zu lassen. »On doit le regretter «, schrieb der Botschafter, "car, si d'une part, il est probable que l'assurance d'une intervention franco-anglaise rendrait prudents ceux des Allemands qui songent à faire violence à la Tchécoslovaquie, on ne saurait

90 Ibid.

91 Ibid.

92 Tbid. S. 888f.

93 Telegramm Nr. 1409 vom 23. März 1938, in: DDF IX/2, Nr. 25, S. 46-48, hier S. 47. $\mathrm{DaB}$ der Botschafter hier irtte, wissen wir heute. Hitler war damals schon entschlossen, die tschechoslowakische Frage »in nicht allzu langer Zeit zu lösen«, d. h. die Sudetendeutschen aus der Republik zu lösen und die Tschechoslowakei zu zerschlagen, siehe HILDEBRAND, Vergangenes Reich, S. $756 \mathrm{ff}$.

94 Ibid. S. 48. 
oublier, d'autre part, que c'est l'incertitude planant sur les intentions britanniques, qui a rendu possible la guerre de 1914 « $^{95}$. André François-Poncet glaubte - ganz im Gegensatz zur britischen Politik -, daß ein »règlement général« - wenn überhaupt - nur erreicht werden könne, wenn die Nationalsozialisten an einem beliebigen Punkt auf entschiedenen Widerstand träfen, der sie vor das Risiko eines europäischen Krieges stelle ${ }^{96}$. Das nationalsozialistische Deutschland unterliege einer "Dynamik «, die die Führer nicht mehr aufhalten könnten. Infolgedessen weiteten sich die Expansionsgrenzen des Reiches immer weiter aus und verschärfte sich ihr Ton immer mehr. Diese Haltung enthielte zwar »une part plus ou moins de bluff «. Gleichwohl müsse ihr mit aller Entschiedenheit von außen entgegengetreten werden, weil im Innern mit keiner Opposition mehr zu rechnen sei. ${ }^{97}$ Der französische Botschafter wollte also den "Bluff « der Reichsregierung nicht mit einem französisch-britischen $» B l u f f \ll$ kontern, sondern er verlangte, daß die französische und die britische Regierung einer möglichen Aggression Deutschlands mit Entschiedenheit entgegentreten, und das hieß in seinen Augen vor einer militärischen Gegenaktion warnen.

Soweit war die Entwicklung im Frühjahr 1938 noch nicht. Die Reichsregierung bzw. die Sudetendeutschen unter der Führung Konrad Henleins beschritten - entsprechend der Vorhersage des Botschafters - zunächst den Verhandlungsweg, indem sie Ende April ihre Forderungen in einem 8-PunkteProgramm vorlegten. Das »Karlsbader Programm « lief im Grunde auf eine »Helvetisierung « der Tschechoslowakei hinaus ${ }^{98}$. André François-Poncet bezweifelte, daß diese Lösung von Dauer sein könne ${ }^{99}$. Henlein und die Sudetendeutschen blickten mehr nach Berlin als nach Prag, denn Deutschland sähen sie als Vaterland. Das 8-Punkte-Programm versuche einerseits den Sudetendeutschen »une indépendance à peu près totale« innerhalb der Tschechoslowakei zu garantieren und andererseits, die staatliche Einheit zu erhalten, um die slawische Mehrheit den deutschen Vorstellungen unterwerfen zu können $^{100}$. Die föderalistische Lösung sollte - so die Meinung des Botschafters -

95 Telegramm Nr. 1490 vom 28. März 1938, in: DDF IX/2, Nr. 65, S. 123. Siehe auch Telegramme Nr. 1438-1440 vom 25. März 1938, in: DDF IX/2, Nr. 40, S. 82. Angesichts dieser Einschätzung ist klar, daß dem französischen Botschafter das Wirken seines britischen Kollegen miBfiel, der ja gerade den Auftrag hatte, die Reichsregierung im unklaren über die britische Politik zu lassen..., siehe NEVILLE, Appeasing Hitler, passim Telegramm Nr. 1531 vom 30. März 1938, in: DDF IX/2, Nr. 81, S. 153-155, hier S. 155.

97 Ibid.

${ }^{98} \mathrm{Zu}$ dem Kongreß der Sudetendeutschen Partei siehe Schulthess' Europäischer Geschichtskalender 1938, S. 233.

99 Telegramme Nr. 1797-1802 vom 25. April 1938, in: DDF IX/2, Nr. 233, S. 492f.

$100 \mathrm{Vgl}$. die ausführliche Analyse der Karlsbader Forderungen in der Depesche Nr. 421 vom 28. April 1938 (Botschafter François-Poncet an Außenminister Bonnet), in: DDF IX/2, Nr. 254, S. 543-552, hier S. 546. 
dem Protektorat Deutschlands unterworfen werden. Abgesehen von der Auflösung der Tschechoslowakei und dem Anschluß der Sudetendeutschen schien ihm das die radikalste Lösung zu sein. Zwischen dieser oder einer gemäßigteren Lösung habe sich, so glaubte André François-Poncet, der Reichskanzler noch nicht entschieden, er werde noch zögern und schwanken. In einem Punkt sei man sich aber einig: Die aktuelle Situation der Sudetendeutschen könne nicht von Dauer sein, das »tschechische Problem《 erfordere dringend eine Lösung ${ }^{101}$.

Vor diesem Hintergrund drängte der Botschafter darauf, daß die tschechoslowakische Regierung die sudetendeutschen Forderungen beantworte ${ }^{102}$. André François-Poncet begründete seine Eile mit der Gefahr eines Zwischenfalles in Böhmen, der den Ereignissen eine dramatische Beschleunigung geben könnte. Während die Sudetendeutschen ihre Forderungen formulierten, (re)formierten Frankreich und Großbritannien ihre Entente. Die französischbritischen Gespräche Ende April 1938 machten André François-Poncet Hoffnung, daß seine Doppelstrategie umgesetzt werden würde. Die »résurrection de l'Entente cordiale ${ }^{103}$ werde die Nationalsozialisten in jedem Fall günstig beeinflussen. "Si elle ne détermine pas ceux-ci à renoncer à leurs ambitions, elle aura du moins mis en lumière les dangers auxquels les exposerait le renouvellement, contre la Tchécoslovaquie, du coup de force du 12 mars et les convaincra peut-être d'ajourner l'exécution de leurs desseins ${ }^{104}$. Nach der Wiederauferstehung der Entente Cordiale werde vor allem die Haltung Italiens und der Ton, den Mussolini gegenüber Hitler bei seinem Rom-Besuch anschlage, über die Entwicklung der deutschen Außenpolitik entscheiden ${ }^{105}$. Daß die Westmächte gemeinsam den europäischen Frieden verteidigen könnten, hoffte André François-Poncet aber vergebens. Die britische Regierung ließ seinen Kollegen in Berlin schon Mitte Mai ein Aide-mémoire übergeben, das gerade die von André François-Poncet geforderte Klarheit vermissen lie ${ }^{106}$. Aber nicht nur die Regierung in London, sondern auch die in Prag folgte seinen Vorstellungen nicht ${ }^{107}$. $\mathrm{Zu}$ allem Überfluß spielte auch noch Rom Berlin in die Hände ${ }^{108}$. Vor diesem Hintergrund erinnerte der Botschafter noch

${ }^{101}$ Ibid. S. 552.

${ }^{102}$ Ibid.

${ }^{103}$ Depesche Nr. 437 vom 3. Mai 1938 (Botschafter François-Poncet an AuBenminister Bonnet), S. 15f., in: CADN, Ambassade Berlin, Série B, Carton 219.

${ }^{104}$ Depesche Nr. 447 vom 5. Mai 1938 (Botschafter François-Poncet an Außenminister Bonnet), S. 9f., in: CADN, Ambassade Berlin, Série B, Carton 219.

${ }^{105}$ Depesche Nr. 437 vom 3. Mai 1938 (Botschafter François-Poncet an Außenminister Bonnet), S. 15f., in: CADN, Ambassade Berlin, Série B, Carton 219.

${ }^{106}$ Telegramm Nr. 2041 vom 12. Mai 1938, in: DDF IX/2, Nr. 322, S. 703f., hier S. 704.

${ }^{107}$ Ibid.

${ }^{108}$ Nach der Mussolini-Rede in Genua hatte der französische Botschafter kaum noch Hoffnung, daß der italienische Ministerpräsident einen guten EinfluB auf den Reichs- 
einmal eindringlich an die Bedeutung der britisch-französischen Zusammenarbeit: »Plus que jamais, c'est donc sur leurs forces réunies et sur leur étroite solidarité que doivent compter la France et l'Angleterre pour organiser la défense de la paix contre une Allemagne qui ne trouve que trop d'encouragements dans l'attitude de l'Italie ${ }^{109}$. Gleichzeitig warnte er vor einer Mobilmachung der tschechoslowakischen Armee, die nach Gerüchten über deutsche Truppenbewegungen an der gemeinsamen Grenze bevorzustehen schien. »Dans l'état actuel des choses, il me semble que ce serait une faute, peut-être la faute que l'Allemagne guette. Mieux vaudrait«, empfahl André François-Poncet in der Mai-Krise, »[de] commencer par invoquer le pacte d'arbitrage de 1925, qui lie jusqu'à présent la Tchécoslovaquie et l'Allemagne. Si l'Allemagne refusait d'appliquer ce pacte, il lui serait plus difficile de prétendre qu'elle a été provoquée « ${ }^{110}$.

Die antideutschen Zwischenfälle Ende April und Anfang Mai ${ }^{111}$ schienen dem Botschafter, wenn nicht provoziert, so doch absichtlich überbewertet, um sie als Vorwand für »un coup de force« verwenden zu können. Die Anspannung der französisch-italienischen Beziehungen nach der Rede von Genua stärke zudem den Einfluß der Extremisten in Deutschland weiter. Das Zögern der Briten verstärke darüber hinaus den Eindruck, daß der günstige Moment zum Losschlagen gekommen sei. Die Nationalsozialisten seien nun bereit, das Risiko eines allgemeinen Krieges einzugehen ${ }^{112}$. André FrançoisPoncet hatte am Abend des 21. Mai den Eindruck, daß sich die Situation wieder entspanne. "Il semble que les démarches répétées et instantes de l'Angleterre et la certitude croissante que la France n'abandonnerait pas les Tchèques si ceux-ci étaient l'objet d'une agression brutale aient un certain effet ${ }^{113}$. Die Möglichkeit einer militärischen Aktion Deutschlands schien dem Botschafter damit zunächst ausgeräumt. Die Krise sei aber noch nicht beendet, sie beginne erst richtig. Der auf Berlin ausgeübte Druck habe zwar das Schlimmste verhindert, aber auch nichts Besseres gebracht ${ }^{114}$. Eine Verbesserung hing von den Vorschlägen Prags ab, das »ernsthafte und substantielle«

kanzler ausüben werde. Siehe Depesche Nr. 513 vom 19. Mai 1938, S. 13, in: CADN, Ambassade Berlin, Série B, Carton 219.

${ }^{109}$ Depesche Nr. 513 vom 19. Mai 1938 (Botschafter François-Poncet an Außenminister Bonnet), S. 13, in: CADN, Ambassade Berlin, Série B, Carton 219.

${ }^{110}$ Telegramme Nr. 2177-2178 vom 21. Mai 1938, 14 Uhr 30, in: DDF IX/2, Nr. 392, S. 816.

111 Schulthess' Europäischer Geschichtskalender 1938, S. 234.

112 Telegramme Nr. 2179-2183 vom 21. Mai 1938, 15 Uhr 15, in: DDF IX/2, Nr. 393, S. $817 \mathrm{f}$.

${ }^{113}$ Telegramme Nr. 2209-2212 vom 23. Mai 1938, in: DDF IX/2, Nr. 421, S. 850f., hier S. 851.

114 Telegramme Nr. 2214-2215 vom 23. Mai 1938, 12 Uhr, in: DDF IX/2, Nr. 425, S. 855 und Telegramme Nr. 2227-2229 vom 24. Mai 1938, 14 Uhr, in: DDF IX/2, Nr. 435, S. 866. 
Vorschläge als mögliche Verhandlungsgrundlage unterbreiten müsse. Gleichzeitig sollten Frankreich und Großbritannien ihre Solidarität stärken, ihre Bevölkerungen auf alle Eventualitäten vorbereiten und auf Prag zurückhaltend einwirken ${ }^{115}$. André François-Poncet sah also in der Mai-Krise eine Bestätigung seiner Doppelstrategie ${ }^{116}$, die er in den folgenden Wochen immer wieder zur Anwendung empfahl.

Einstweilen schien André François-Poncet das Sudetenproblem auf einer Zwischenstufe angekommen zu sein. »Mais ce temps d'arrêt n'est qu'un répit. La tension germano-tchèque reste sérieuse et, si la crise est dépassée, les milieux dirigeants du Troisième Reich ne paraissent guère disposés à l'oublier. En fait, rien n'autorise à penser que le conflit entre Berlin et Prague soit en voie de s'apaiser « ${ }^{117}$. Die nationalistische Presse bleibe so gewalttätig in ihren Angriffen wie arrogant in ihren Forderungen. Stellte sich die Frage, ob sich die Tschechoslowaken und mit ihnen Europa mit einem Rückzugsgefecht oder einer Angriffsvorbereitung konfrontiert sähen ${ }^{118}$. André François-Poncet hatte den Eindruck, daß das Reich eher den Gegner ins Visier nehme, als ihm das Feld zu überlassen, eher eine Gegenattacke als einen strategischen Rückzug vorbereitete. Gleichzeitig sollten die öffentliche Meinung in Deutschland und in Großbritannien für die Sache der Sudetendeutschen gewonnen werden ${ }^{119}$. Die Taktik der Reichsregierung schien dem Botschafter aber nach wie vor unklar. "Tout ce que l'on peut affirmer sans trop courir le risque de se tromper, « schloß André François-Poncet, »c'est que le Reich est loin de considérer la partie comme jouée et se prépare, dans un secret qui n'est pas de bon augure, à en affronter les prochains épisodes « ${ }^{120}$.

Als nächstes stand Mitte Juni der dritte Teil der Kommunalwahlen in der Tschechoslowakei auf dem Programm. Die Situation schien nach Einschätzung des französischen Botschafters im Vorfeld unverändert ${ }^{121}$. Prag müsse - so seine Forderung - den Sudetendeutschen nach den Wahlen vom 12. Juni Vorschläge unterbreiten, die die internationale Meinung vom guten Willen, der Loyalität und dem liberalen Geist der tschechoslowakischen Regierung überzeugten. Gleichzeitig müßten Paris und London in ihrer Haltung hart bleiben und dürften nicht den Eindruck erwecken, daß sie von

115 Telegramm Nr. 2232 vom 24. Mai 1938, in: DDF IX/2, Nr. 438, S. 870-872, hier S. 872.

${ }^{116}$ Depesche Nr. 523 vom 24. Mai 1938 (Botschafter François-Poncet an AuBenminister Bonnet), in: DDF IX/2, Nr. 441, S. 874-885, hier S. 885.

${ }^{117}$ Depesche Nr. 559 vom 31. Mai 1938 (Botschafter François-Poncet an Außenminister Bonnet), S. 1, in: CADN, Ambassade Berlin, Série B, Carton 219.

118 Ibid.

${ }^{119}$ Ibid. S. 1f. und S. 9 f.

${ }^{120}$ Ibid. S. 10f.

${ }^{121}$ Depesche Nr. 591 vom 9. Juni 1938 (Botschafter François-Poncet an Außenminister Bonnet), S. 1, in: CADN, Ambassade Berlin, Série B, Carton 219. 
ihrer energischen Resolution vom 21. Mai abrückten ${ }^{122}$. Hier zeigt sich erneut die deutschlandpolitische Doppelstrategie André François-Poncets, die er auch im Sommer 1938 weiter verfolgen wollte, da er - trotz der "période de tranquillité relative" - den deutsch-tschechoslowakischen Konflikt nicht gelöst und auch nicht auf dem Weg der Lösung sah $^{123}$. Der Konflikt sei zwar "suspendiert«, aber die Krise nach wie vor "latent« und »bedrohlich«. Sie werde nach dem Erfolg der Sudetendeutschen Partei bei den Kommunalwahlen im Sudetengebiet nach Ansicht des Botschafters wieder in Gang gesetzt werden. Infolgedessen habe die »campagne contre Prague [...] les plus hauts étiages de la haine et de la fureur « erreicht ${ }^{124}$. Vor diesem Hintergrund empfahl André François-Poncet erneut, seine deutschlandpolitische Doppelstrategie anzuwenden: "Plus que jamais, en effet, le maintien de la paix exige de Londres et de Paris la persévérance dans la fermeté et dans la vigilance, tandis que les dirigeants de Prague sont soumis à une redoutable épreuve de sang-froid, de souplesse et de prudence ${ }^{125}$. Dieser Empfehlung verlieh der Botschafter Nachdruck, indem er Mitte Juni nach Paris telegrafierte, daß Reichskanzler Hitler "à l'action, au besoin à l'action belliqueuse« entschlossen sei und daß dieser nur noch »le moment favorable « abwarte ${ }^{126}$. Anfang August könnte eine »kritische Periode« eröffnet werden.

Si l'on veut retenir $M$. Hitler sur la pente dangereuse où il semble s'être engagé et fortifier l'action que s'efforcent d'exercer sur lui ses conseillers les plus modérés, il est nécessaire qu'il devienne de plus en plus évident qu'une entreprise de brutalité, ayant pour but réel, non pas seulement de protéger des frères de race maltraités, mais de rayer la Tchécoslovaquie de la carte d'Europe, se heurterait immanquablement à la résistance d'une coalition puissante et résolue ${ }^{127}$.

Der entschiedene Widerstand einer mächtigen Koalition schien dem französischen Botschafter nicht genug. »Il est également nécessaire que le cabinet de Prague manœuvre avec habileté. L'Allemagne«, wiederholte André FrançoisPoncet seine Interpretation der deutschen Politik, »cherche à renverser les positions morales, à faire apparaître les Tchèques comme un peuple intransigeant, borné, buté, persécuteur, incapable de consentir aux Sudètes l'octroi des libertés les plus naturelles; elle travaille à leur attribuer les torts et à les rendre antipathiques ${ }^{128}$. Um dieses Kalkül zu durchkreuzen, müßten die Tschechen

${ }^{122}$ Vgl. Telegramm Nr. 2409 vom 9. Juni 1938, in: DDF IX/2; Nr. 534, S. 1048-1050, hier S. 1049.

${ }^{123}$ Telegramm Nr. 2489 vom 16. Juni 1938, in: DDF X/2, Nr. 45, S. 86-88, hier S. 87.

${ }^{124}$ Depesche Nr. 605 vom 14. Juni 1938 (Botschafter François-Poncet an Außenminister Bonnet), S. 6, in: CADN, Ambassade Berlin, Série B, Carton 219.

125 Ibid. S. 7.

126 Telegramm Nr. 2489 vom 16. Juni 1938, in: DDF X/2, Nr. 45, S. 86-88, hier S. 87.

${ }^{127}$ Ibid. S. 88.

${ }^{128}$ Ibid. 
"la preuve d'une bonne foi et d'une bonne volonté« erbringen, bereit »à toutes les concessions raisonnables, sauf à la servitude ou au suicide de leur état«.

André François-Poncet sah sich in seiner Einschätzung und Haltung durch den Reichsaußenminister bestätigt ${ }^{129}$. Nach dem Gespräch mit von Ribbentrop machte sich André François-Poncet keine Illusionen mehr über die relative Beruhigung und Entspannung der deutsch-tschechoslowakischen Beziehungen seit den Kommunalwahlen Mitte Juni ${ }^{130}$. Die Gefühle und Absichten der Führer des »Dritten Reiches« schienen dem Botschafter unverändert: »Une rancune tenace, une haine profonde, un ardent désir de vengeance, tels sont aujourd'hui encore les sentiments dominants à l'égard de Prague des chefs nazis ${ }^{131}$. Die Tschechoslowakei erscheine ihnen »comme le trait d'union entre les forces qui cherchent à contenir la poussée du germanisme, comme un noyau autour duquel pouvaient se cristalliser les résistances, comme une pierre d'achoppement éventuelle pour les ambitions allemandes ${ }^{132}$. Dementsprechend sei ihre Abneigung gegen das Land gewachsen. Dieser Stachel im deutschen Fleisch müsse, koste es was es wolle, ausgerissen werden. Das sei seit der Mai-Krise unverändert der »Geisteszustand « der »Nazi-Chefs«. André François-Poncet schloß aus der Analyse, daß sich das Reich nicht mehr mit einer »Helvetisierung « der Tschechoslowakei zufriedengeben würde. Ihre Teilung und der Anschluß der sudetendeutschen Gebiete an das Reich sei das unausgesprochene Ziel. Vor diesem Hintergrund glaubte der französische Botschafter nicht an eine dauerhafte Entspannung ${ }^{133}$.

André François-Poncet erwartete, daß die Krise erst Mitte August weitergehen werde ${ }^{134}$. Dann werde Deutschland die erstbeste Gelegenheit nutzen, um gegen die Tschechoslowakei loszuschlagen. In der Zwischenzeit werde Deutschland das diplomatische Feld bereiten und die Mitarbeit oder wenigstens die Zurückhaltung Italiens, Ungarns, Polens, Rumäniens, Jugoslawiens und selbst Großbritanniens zu errreichen versuchen. "Le problème qui se pose est donc«, schloß der Botschafter, »de trouver les moyens de faire échec aux plans insensés qu'Hitler roule dans sa tête ${ }^{135}$. Der Botschafter wiederholte seine Ansicht, daB nur eine starke antideutsche Koalition die Reichsführung zurückhalten könne. »Il serait donc souhaitable que l'Angleterre, la Russie, la Petite-Entente, les États-Unis, à défaut d'autres, tinssent, dans les semaines qui

${ }^{129}$ Siehe Telegramm Nr. 2600 vom 23. Juni 1938 , in: DDF X/2, Nr. 79, S. 142-144 sowie Depesche Nr. 666 vom 23. Juni 1938 (Botschafter François-Poncet an Außenminister Bonnet), in: DDF X/2, Nr. 83, S. 149-152.

${ }^{130}$ Depesche Nr. 694 vom 30. Juni 1938 (Botschafter François-Poncet an Außenminister Bonnet), S. 4, in: CADN, Ambassade Berlin, Série B, Carton 219.

${ }^{131}$ Ibid. S. $5 f$.

${ }^{132}$ Ibid.

${ }^{133}$ Ibid. S. 9.

${ }^{134}$ Telegramm Nr. 2760 vom 5. Juli 1938, in: DDF X/2, Nr. 150, S. 281-283, hier S. 281.

${ }^{135}$ Ibid. S. 282. 
s'approchent, un langage non équivoque ${ }^{136}$. Gleichzeitig dürfe Prag Berlin keinen Vorwand liefern, der die moralische Lage Deutschlands verbessert.

Il faut que, d'avance, aux yeux du monde entier, et particulièrement anglo-saxon, l'opération allemande apparaisse comme une action de brutalité et de brigandage. Pour cela, il n'est pas nécessaire seulement de présenter bientôt aux Sudètes un statut aussi large et libéral que possible. À mon avis, il serait, en outre, opportun que l'Angleterre suggérât l'idée d'une neutralisation de la Tchécoslovaquie, garantie, dans l'intérêt de la paix de l'Europe, par les grandes puissances. Je ne dis pas qu'une telle initiative suffirait à détourner Hitler de ses funestes projets. Elle le gênerait certainement. Elle gênerait l'opinion publique allemande. Elle créerait, si elle était repoussée, un courant hostile à l'Allemagne, dans l'opinion internationale $\mathbf{e}^{137}$.

André François-Poncet zielte also mit seiner Doppelstrategie nicht nur auf die deutsche Tschechoslowakeipolitik, sondern auch auf die öffentliche Meinung ab, die gegen Hitler bzw. Deutschland gerichtet werden müsse. Der Botschafter drängte deshalb, ganz im Gegensatz zu seinem britischen Kollegen, der die deutsche Mobilmachung abwarten wollte, auf eine italienisch-englische Vermittlung ${ }^{138}$. Nach der Mobilmachung schien es André François-Poncet dafür zu spät. »C'est avant, qu'il faut agir, si l'on veut empêcher d'irrémédiables catastrophes ${ }^{139}$.

Wenige Tage später kündigte der britische Premierminister Chamberlain eine Vermittlungsmission Lord Runcimans an, der am 3. August in Prag eintraf ${ }^{140}$. André François-Poncet vertraute nicht auf diese sich abzeichnende Entspannung ${ }^{141}$. Der Aufschub werde längstens bis zum Reichsparteitag in Nürnberg währen ${ }^{142}$. »Encore faut-il«, forderte der Botschafter von der französischen Regierung für diese Zwischenzeit, »que ce répit soit utilisé sans retard et avec énergie par la diplomatie franco-britannique, et non pas pour faciliter au Führer l'emploi ultérieur de la violence, mais, au contraire, pour lui en barrer la route. Sinon, la pause en question ne sera qu'une accalmie avant l'orage ${ }^{143}$. Der Sturm werde - so schien es dem Botschafter - im Herbst losbrechen, wenn die militärischen Vorbereitungen abgeschlossen seien. Daß

${ }^{136}$ Ibid.

137 Ibid.

${ }^{138}$ Siehe Telegramm ohne Nr. vom 21. Juli 1938, in: DDF X/2, Nr. 264, S. 452-456, hier S. $454 \mathrm{f}$.

${ }^{139}$ Ibid. S. 455.

${ }^{140}$ Siehe Schulthess' Europäischer Geschichtskalender 1938, S. 307, 240.

${ }^{141}$ Siehe Telegramm ohne Nr. vom 26. Juli 1938, in: DDF X/2, Nr. 271, S. $493-495$ und Telegramm ohne Nr. vom 26. Juli 1938, in: DDF X/2, Nr. 269, S. 490-492.

${ }^{142}$ Telegramm ohne Nr. vom 1. August 1938, in: DDF X/2, Nr. 312, S. 560-562, hier S. 561.

${ }^{143}$ Siehe Telegramm ohne Nr. vom 26 . Juli 1938, in: DDF X/2, Nr. 271, S. 493-495, hier S. 495. 
sie Teil eines »énorme bluff« sein könnten, gestand der Botschafter zu. Um ihm zu begegnen, müsse man ihn aber ernst nehmen ${ }^{144}$.

Das war das Problem. Die französische Luftwaffe konnte - wie die Armee insgesamt - der deutschen nicht Paroli bieten. General Vuillemin sagte dem Botschafter im August 1938 am Ende seines Deutschlandbesuches: »S'il y a la guerre, comme vous le dites, fin septembre, au bout de 15 jours, il n'y aura plus un avion français! ${ }^{145}$. Offensichtlich hatte die zur Schau gestellte Luftwaffe des Reiches ihren Eindruck auf den französischen Besucher nicht verfehlt ${ }^{146}$. Die Konsequenzen liegen auf der Hand: Der Luftwaffengeneral dürfte nach seiner Rückkehr nach Paris der von André François-Poncet propagierten Politik nicht das Wort geredet haben. Im Gegenteil! Zugleich wäre ihr - so sie denn weiter verfolgt worden wäre - die materielle Grundlage entzogen worden, so daß diese Politik zu dem gewordem wäre, was sie in den Augen des Botschafters gerade nicht hätte sein sollen: ein Bluff. Daß die Reichsführung angesichts dieser militärischen Stärkeverhältnisse vor einer "solution extrême« nicht zurückschrecken würde, war dem Botschafter infolgedessen klar ${ }^{147}$. »Ce n'est pas à dire, « schränkte André François-Poncet aber ein, "qu'ils veuillent la guerre et feront la guerre. Ils comptent plutôt qu'il leur sera possible d'éviter la guerre, ou la généralisation de la guerre. Ils souhaitent de localiser le conflit ${ }^{148}$. Die Drohung mit einer Ausweitung des Konfliktes war der Schlüssel zur Sicherung des Friedens. Der drohte allerdings durch die innenpolitische Krise in Frankreich unbrauchbar zu werden. André François-Poncet warnte sein Land, Hitler eine günstige Gelegenheit zur Verwirklichung seiner Pläne zu bieten ${ }^{149}$. Die lagen - wie erwartet - bis zum Nürnberger Reichsparteitag auf Eis. »Mais il serait prématuré d'en tirer des conclusions optimistes quant à un avenir un peu plus lointain. Rien n'autorise encore de penser que la situation soit entrée dans la voie conduisant à un règlement pacifique ${ }^{150}$. Die vorgeschlagenen Kantone für die Sudetendeutschen würden als »unzureichend« beurteilt. Man wolle keine "autonomie fractionée et relative " für die deutsche Volksgruppe, sondern eine »autonomie territoriale«. Gleichwohl würden die Vorschläge aus

${ }^{144}$ Telegramm ohne Nr. vom 9. August 1938 , in: DDF X/2, Nr. 344 , S. 618-622, hier S. $621 f$.

${ }^{145}$ FRANÇOIS-PONCET, Chronique, 18. [August 1938].

${ }^{146}$ Siehe Telegramme ohne Nr. vom 18. August 1938, in: DDF X/2, Nr. 401 und 402, S. 704-707 sowie die Analyse vom 21. August 1938, in: DDF X/2, Nr. 429, S. 760-762.

${ }^{147}$ Siehe die Analyse der militärischen Stärke Deutschlands in der Depesche Nr. 882 vom 18. August 1938, in: DDF X/2, Nr. 412, S. 724-733.

${ }^{148}$ Telegramm ohne Nr. vom 23. August 1938 , in: DDF X/2, Nr. 441, S. 784-786, hier S. 785 .

${ }^{149}$ Ibid. S. 786.

${ }^{150}$ Telegramme Nr. 3328-3331 vom 3. September 1938, in: CADN, Ambassade Berlin, Série B, Carton 162. 
Prag nicht kategorisch zurückgewiesen, sondern so beantwortet, daß weitere Diskussionen möglich seien. Anfang September hatte André François-Poncet den Eindruck, daß sich die Situation verschlechtere. Hitler wünsche nicht, zu einem Arrangement zu kommen. Außerdem gingen die militärischen Vorbereitungen des Reiches weiter ${ }^{151}$. In seiner Eröffnungsrede des Nürnberger Reichsparteitags am 6. September 1938 erwähnte der Reichskanzler zwar weder die Tschechoslowakei noch die Sudetendeutschen, wies aber die GemäBigten seiner Ratgeber in die Schranken ${ }^{152}$. »Loin donc «, schloß André François-Poncet seine Analyse, »d'apporter dans la situation actuelle un élément d'apaisement et de l'éclairer d'une lueur rassurante, la proclamation de ce matin confirme et renforce tous les soupçons auxquels donne lieu la conduite de M. Hitler, tout ce que l'on sait des arrière-pensées qui l'animent ${ }^{153}$. Der Reichskanzler schien André François-Poncet "schwere Entscheidungen " getroffen zu haben oder noch zu treffen ${ }^{154}$. Angesichts diesen Eindrucks hielt der Botschafter die Lage für aussichtslos ${ }^{155}$.

André François-Poncet glaubte also nicht (mehr), den Wunsch einer Verständigung bei der Reichsführung ausmachen zu können. Wie sollten dann Deutschlands Bedingungen erfüllt werden, wie eine Gewaltanwendung verhindert werden, außer durch die Erfüllung eben dieser deutschen Forderungen? Und wie sollte danach die Tschechoslowakei zur Annahme der Bedingungen gebracht werden? »J'avoue «, bekannte der Botschafter resigniert, »ne pas apercevoir l'issue honorable qui permettrait de sortir pacifiquement d'une telle situation; la logique des choses, à moins de circonstances imprévues et quasi miraculeuses, semble ainsi conduire à des événements dramatiques et prochains ${ }^{156}$. Die »dramatischen Ereignisse « würden sich Mitte oder Ende September abspielen. Das schien das Ende der Verständigungsbemühungen André François-Poncets zu sein.

Neue Hoffnung machten ihm die wenige Tage später veröffentlichten Vorschläge der tschechoslowakischen Regierung ${ }^{157}$. Sie habe die Reichsführung in Verlegenheit gebracht. Eine Einigung über die Zusicherung einer

151 Telegramme Nr. 3363-3365 vom 6. September 1938, in: CADN, Ambassade Berlin, Série B, Carton 162. Siehe auch Telegramm 3336-3337 vom 3. September 1938, in: DDF $\mathrm{XI} / 2$, Nr. 2, S. 4.

152 Text in Schulthess' Europäischer Geschichtskalender 1938, S. 132f.

${ }^{153}$ Vgl. Telegramm ohne Nr. vom 6. September 1938, S. 3, in: CADN, Ambassade Berlin, Série B, Carton 162.

154 Telegramme Nr. 3401-3403 vom 10. September 1938, in: CADN, Ambassade Berlin, Série B, Carton 162. André François-Poncet hatte schon am 6. September gemeldet, daB der Generalstab den »Jour X « vom 28. auf den 24 . September vorziehen sollte, vgl. Telegramm ohne Nr. vom 6. September 1938, in: DDF XU/2, Nr. 21, S. 29-31.

${ }^{155}$ Telegramm ohne Nr. vom 6. September 1938, in: DDF XI/2, Nr. 22, S. 31-35, hier S. 32.

${ }^{156}$ Ibid.

${ }^{157}$ Telegramme Nr. 3404-3306 vom 10. September 1938, 13 Uhr 30, in: CADN, Ambassade Berlin, Série B, Carton 162. 
großzügigen Autonomie schien doch erreichbar. "Si l'Allemagne passe outre, on ne pourra plus douter qu'elle ne poursuive d'autres objectifs et qu'elle n'ait d'autres ambitions. Et sa position morale en portera le poids. Elle le sent si bien que tout son effort actuel vise à prêter aux Tchèques un rôle de bourreaux

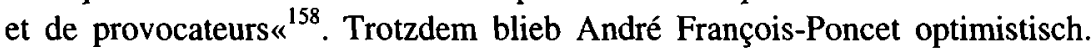
»Je garde l'impression qu'un suprême effort sera tenté, sinon de l'extérieur, du moins du dedans, par les partisans de la paix, pour retenir le Chancelier au bord du drame ${ }^{159}$. Selbst die kriegerische, ultimative Schlußrede Hitlers auf dem Nürnberger Reichsparteitag konnte den Optimismus des Botschafters nicht vollständig zerstören, enthielt sie doch in seinen Augen eine Lösung, die die Grenzen der Tschechoslowakei respektiere, wenn die Sudetendeutschen eine »vollständige Autonomie « bekämen ${ }^{160}$. Trotz dieser wohlwollenden Interpretation der Hitler-Rede glaubte André François-Poncet kaum, daß sich der Reichskanzler von seinem Entschluß, militärisch in der Tschechoslowakei zu intervenieren, abbringen lasse ${ }^{161}$. Da der Reichskanzler die Unruhen vom 13. September nicht ausnutzte, glaubte André François-Poncet, »que M. Hitler, à moins que les événements ne lui forcent la main, désire gagner encore quelques jours « ${ }^{162}$. Dementsprechend ging der Reichskanzler auf das Angebot des britischen Premierministers ein, die offenen Fragen bei einem Treffen auf dem Obersalzberg zu besprechen ${ }^{163}$. Das Angebot vom 14. September und das Treffen am 15. schienen dem Botschafter den Deutschen eine gewisse Zurückhaltung auferlegt zu haben ${ }^{164}$. $\gg$ Herr Hitler « wollte eigentlich der Reichswehr den Einmarsch für den 27. September befehlen. Die Ereignisse haben aber sein Kalkül gestört:

Les troubles qui avaient été préparés dans la région des Sudètes et qui ont éclaté, selon le programme convenu, après le congrès de Nuremberg, ont pris tout de suite une ampleur et causé un nombre de victimes très supérieur à ce que l'on avait pensé. La visite inattendue de Sir Neville Chamberlain a achevé de bouleverser le dispositif initial. Actuellement, le Führer et ses conseillers paraissent surtout préoccupés de profiter des circonstances pour aller le plus vite et le plus loin possible, comme ils l'étaient au moment où ils ont précipité la phase finale de l'affaire d'Autriche ${ }^{165}$.

${ }^{158}$ Ibid.

${ }^{159} \mathrm{Vgl}$. Telegramme Nr. 3411-3416 vom 10. September 1938, 21 Uhr, in: DDF XI/2, Nr. 73, S. 123f., hier S. 124.

${ }^{160}$ Vgl. Telegramme Nr. 3446-3451 vom 13. September 1938, in: DDF XV/2, Nr. 108, S. 179f. Text der Rede in Schuithess' Europäischer Geschichtskalender 1938, S. 135ff.

${ }^{161}$ Telegramme Nr. 3454-3459 vom 13. September 1938, in: DDF XI/2, Nr. 114, S. $187 \mathrm{f}$ und Telegramm ohne Nr. vom 13. September 1938, in: DDF XU/2, Nr. 116, S. 189.

${ }^{162}$ Telegramm Nr. 3469 vom 14. September 1938, in: DDF XI/2, Nr. 134, S. 212.

${ }^{163}$ Schulthess' Europäischer Geschichtskalender 1938, S. 142.

${ }^{164}$ Telegramme Nr. 3480-3483 vom 15. September 1938, in: DDF XI/2, Nr. 151, S. 231.

${ }^{165}$ Telegramm ohne Nr. vom 15. September 1938, in: CADN, Ambassade Berlin, Série B, Carton 162. 
Gleichzeitig gingen die militärischen Vorbereitungen weiter ${ }^{166}$. Ein »allgemeiner Krieg " werde in Berlin zwar für unwahrscheinlich, ein "lokaler Krieg" aber für wahrscheinlich gehalten. "Car on ne suppose pas que M. Benès accepte bénévolement la cession du territoire des Sudètes, à laquelle il faudra joindre sans doute le district de Teschen et une portion de la Slovaquie, que la Pologne et la Hongrie ne manqueront pas d'exiger, c'est-à-dire le démembrement de la Tchécoslovaquie « ${ }^{167}$. Der tschechoslowakische Ministerpräsident werde sich für einen Krieg entscheiden, der in Berlin zu führen gewünscht werde. »Hitler brûle de faire sentir sa puissance militaire, non seulement pour se venger des Tchèques, mais encore pour effrayer les états de l'Europe centrale, pour accroittre son prestige au dehors et au dedans ${ }^{168}{ }^{168}$.

Der französische Botschafter glaubte indes immer noch, daß eine friedliche Regelung möglich sei. Allerdings gab er sich mit atmosphärischen Verbesserungen nicht zufrieden, er wollte - angesichts der dem Frieden zu bringenden Opfer - mehr. »Il est, sans doute, superflu d'insister sur l'aspect douloureux et pénible que revêt, à nos yeux, le drame tchécoslovaque. La contrepartie devrait être trouvée dans l'établissement d'un modus vivendi [Hervorhebung im Original, cws], d'un règlement général, valable pour plusieurs années, entre les états démocratiques et les états autoritaires ${ }^{169}$. André François-Poncet brachte den Gedanken eines allgemeinen Abkommens wieder ins Gespräch, der - wie gesehen - 1937 immer wieder diskutiert worden war. Daß die Zugeständnisse Deutschland einen Triumph bereiten, seine Kühnheit, seine Selbstsicherheit und seine Mißachtung der anderen, die sich durch eine Steigerung seiner Ambitionen und Ansprüche bemerkbar machen werde, steigern werden, schien dem Botschafter klar ${ }^{170}$.

Vor diesem Hintergrund schien André François-Poncet die Gefahr eines Krieges keineswegs gebannt. Wenn Großbritannien und Frankreich heute einen Krieg vermieden, weil sie schlecht darauf vorbereitet seien, dann täten sie ohne Zweifel gut daran, ihre militärischen, wirtschaftlichen und diplomatischen Vorbereitungen zu beschleunigen und abzuschließen. »Car il pourrait arriver que le destin de l'Europe se jouât finalement dans une nouvelle bataille des Champs catalauniques ou dans une bataille de Poitiers ${ }^{171}$. Dieser Hinweis auf die säkularen Schlachten der französischen Geschichte verdeutlicht die Bedeutung, die der französische Botschafter der bevorstehenden Auseinandersetzung zumaß. Vor diesem Hintergrund ist ver-

\footnotetext{
166 Telegramme Nr. 3497-3498 vom 17. September 1938, in: DDF XI/2, Nr. 182, S. 277

${ }^{167}$ Telegramm Nr. 3534 vom 20. September 1938, in: DDF XI/2, Nr. 237, S. 366-368, hier S. 367.

168 Ibid.

${ }^{169}$ Ibid

${ }^{170}$ Ibid

${ }^{171}$ Ibid.
} 
ständlich, daß er - zugunsten der Vorbereitung auf diese Auseinandersetzung zwischen den demokratischen und autoritären Staaten - zu einer Vermeidung eines Krieges wegen der Tschechoslowakei bereit war, um Vorbereitungszeit für die Demokratien zu gewinnen. Die müßten allerdings die gewonnene Zeit für die wohl unabwendbare Auseinandersetzung nutzen. In diesem Sinne wirkte André François-Poncet in den letzten Wochen seiner Berliner Botschafterzeit auf eine Vermeidung eines Krieges, ja auf eine gewisse Verständigung hin, um Zeit für eine umfassende Vorbereitung für den später unvermeidlichen Krieg zu gewinnen. Diese Taktik sollte bei der Bewertung seiner Politik im Hinterkopf behalten werden.

André François-Poncet blickte dem zweiten, in Godesberg stattfindenden Treffen Hitlers und Chamberlains mit keinem großen Optimismus entgegen. Die Reichsführung hatte nach seiner Ansicht auf einen Gewalteinsatz nicht verzichtet $^{172}$. Der französische Botschafter fürchtete, daß Deutschland ein doppeltes Spiel spiele. "L'Allemagne, en même temps que la carte de la paix, joue la carte de la guerre, du moins celle de la guerre localisée ${ }^{173}$. Vor diesem Hintergrund war André François-Poncet skeptisch, daß der britische Premier die den weitreichenden Zugeständnissen entsprechenden Kompensationen erhalten werde. "Arrivera-t-il à arracher au Reich ce qui devrait être, dès maintenant, la compensation normale des sacrifices de la Tchécoslovaquie, à savoir la promesse d'arrêter la guérilla des frontières, la renonciation à l'invasion militaire et un commencement de démobilisation ${ }^{174}$. Bemerkenswert ist, daß der französische Botschafter innerhalb von zwei Tagen die von ihm erwarteten Gegenleistungen des Reiches auf ein Minimum reduzierte. Von einem Modus vivendi, einem allgemeinen Abkommen war keine Rede mehr. Und selbst an das Minimum glaubte er nicht mehr. Die Ereignisse gaben ihm recht. Reichskanzler Hitler war mit dem Erreichten unzufrieden und verlangte - zur Überraschung der britischen Besucher - mehr. Daß Chamberlain infolgedessen den Verhandlungsort verlassen wollte, habe den »Führer« und seine Berater so überrascht und geschockt, daß sie die Verabschiedung am nächsten Morgen bis in die Nacht verlängerten und »M. Hitler« seine unnachgiebige Haltung veränderte ${ }^{175}$.

Gleichzeitig hatte die Mobilmachung der Tschechoslowakei die militärische Lage verändert. "L'Allemagne s'est trouvée brusquement en face de la perspective d'un effort maximum et sur plusieurs fronts, pour lequel elle n'est peut-être pas encore au point. Si M. Hitler ne l'a pas vue de lui-même, il y a,

172 Depesche Nr. 1003 vom 20. September 1938 (Botschafter François-Poncet an Außenminister Bonnet), in: DDF XI/2, Nr. 244, S. 378-384, hier S. 384.

${ }^{173}$ Telegramm Nr. 3557 vom 22. September 1938, in: DDF XI/2, Nr. 291, S. 444-446, hier S. 446.

${ }^{174}$ Ibid.

${ }^{175}$ Telegramme Nr. 3575-3578 vom 24. September 1938, in: DDF XI/2, Nr. 329, S. $501 f$. 
sans doute des gens qui le lui auront montré. Et c'est peut-être ce qui l'aura décidé à accepter l'idée d'un délai supplémentaire ${ }^{176}$. Diese $» z u s a ̈ t z l i c h e$ Frist « schien dem Botschafter »une importante concession« des »Herrn Hitler« gegenüber dem »Herrn Chamberlain«, da er anstatt einer sofortigen militärischen Okkupation einen sechstägigen Aufschub gewährte, der eine Evakuierung der Gebiete erlaube ${ }^{177}$.

André François-Poncet führte diese Entscheidung darauf zurück, daß die Reichsregierung fürchte, der lokale Krieg könnte sich doch zu einem allgmeinen ausweiten ${ }^{178}$. Angesichts der Einschätzung warnte der Botschafter die tschechoslowakische Regierung, nicht in die Falle zu tappen und sich nicht dem Vorwurf des schlechten Willen auszusetzen. Das konnte nur heißen, daß André François-Poncet ein Eingehen auf die deutschen Forderungen erwartete. Angesichts des tschechoslowakischen Zögerns, die sudetendeutschen Gebiete bis zum 1. Oktober zu räumen, machte der französische Botschafter einen Vorschlag, um im letzten Moment das Schlimmste zu verhindern: Die sudetendeutschen Gebiete sollten von einer internationalen Macht besetzt werden und zwar sofort ${ }^{179}$. Frankreich und Großbritannien sollten »Herrn Hitler» darüber hinaus die in Aussicht gestellte Abtretung der sudetendeutschen Gebiete garantieren. Allerdings sei die Frist für die Evakuierung zu kurz, sie müsse auf den 1. November verlängert werden. Die deutschen Truppen dürften jedoch, so der Vorschlag André François-Poncets, am 1. Oktober zumindest die Region Asch oder einen Teil des Egerlandes besetzen. Wenn "Herr Hitler « gleichwohl am 1. Oktober zu einer militärischen Besetzung schreite, dann müßten Großbritannien und Frankreich annehmen, daß er einen Krieg provozieren wolle und sich dementsprechend verhalten... Reichskanzler Hitler schien sich indes auf keine Verhandlungen mehr einlassen zu wollen ${ }^{180}$. Vielmehr bereitete er die Deutschen und die Welt auf den bevorstehenden Einmarsch vor ${ }^{181}$. Gleichwohl entschloß sich der französische Außenminister in der Nacht zum 28. September, seinen Botschafter in Berlin zu einem »dernier effort pour éviter l'irréparable« aufzufordern ${ }^{182}$. André François-Poncet wurde am 28. September um 11 Uhr 15 vom Reichskanzler empfangen, der

${ }^{176}$ Ibid. S. 502.

${ }^{177}$ Telegramme Nr. 3580-3583 vom 24. September 1938, in: DDF XI/2, Nr. 331, S. 504f.

${ }^{178}$ Ibid.

179 Telegramme Nr. 3627-3629 vom 27. September 1938, in: DDF XI/2, Nr. 385, S. 589.

180 Vgl. die Erklärungen Nevile Hendersons gegenüber André François-Poncet in den Telegrammen Nr. 3631-3632 vom 27. September 1938, in: DDF XI/2, Nr. 387, S. 592.

${ }^{181} \mathrm{Vgl}$. die Analyse der Sportpalast-Rede vom 26. September, in: Telegramm Nr. 3630 vom 27. September 1938, in: DDF XI/2, Nr. 386, S. 590f. und Telegramm Nr. 3633 vom 27. September 1938, in: DDF XI/2, Nr. 397, S. 601-603.

182 Siehe "Note du Ministre« vom 27. September 1938, in: DDF XI/2, Nr. 400, S. 605 f. sowie Telegramme Nr. 847-852 des Außenministers Georges Bonnet an den Botschafter André François-Poncet vom 28. September 1938, $1 \mathrm{Uhr}$, in: DDF XI/2, Nr. 413, S. $629 f$. 
sich von der Demarche - so jedenfalls der Eindruck des Botschafters - ein wenig erschüttert zeigte bzw. zumindest zu schwanken anfing ${ }^{183}$. Ein Anruf Mussolinis, der Hitler um einen Aufschub bat, schien ebenfalls Eindruck gemacht zu haben, jedenfalls zeigte sich der Reichskanzler in dem Meinungsaustausch anschließend nachgiebiger. Aus dem lebhaften Gespräch schöpfte André François-Poncet Hoffnung, »un faible espoir, mais tout de même un espoir « ${ }^{184}$. Der Hoffnungsschimmer des Botschafters wurde nicht enttäuscht: Reichskanzler Hitler lud am Nachmittag des 28. die Ministerpräsidenten Frankreichs, Großbritanniens und Italiens zu einer Konferenz nach München $e^{18}{ }^{185}$.

André François-Poncet nahm als Mitglied der französischen Delegation nur zeitweise an den Gesprächen der vier Regierungschefs teil ${ }^{186}$. Die einigten sich in der Nacht vom 28. auf den 29. September auf ein Abkommen, das die Abtretung der sudetendeutschen Gebiete an das Reich bis zum 10. Oktober vorsah. Die Einzelheiten sollte eine Kommission mit den Tschechoslowaken klären ${ }^{187}$. Die Verhandlungen der Kommission sind an dieser Stelle nicht en détail wiederzugeben, da der französische Botschafter in diesem Zusammenhang weder seine deutschlandpolitischen Vorstellungen änderte noch äußerte. Festzuhalten bleibt, daß sich André François-Poncet des "caractère si pénible« des Münchner Abkommens bewußt war. "Elle [la Tchécoslovaquie, cws] est «, schloß der Botschafter, »amputée d'une jambe, mais l'autre lui est conservée; et surtout le malade survit et pourra se rétablir ${ }^{188}$. Diese optimistische Bewertung des Münchner Abkommens und der Zukunft der Tschechoslowakei verschlechterte sich im Laufe der Kommissionsverhandlungen ${ }^{189}$. "Manifestement «, telegrafierte der Botschafter am 5. Oktober nach Paris, »l'Allemagne s'applique à réduire la Tchécoslovaquie à entrer dans son orbite et à lui enlever tout moyen d'échapper, à l'avenir, à son emprise ${ }^{190}$. Die »neue« Tschechoslowakei schien dem Botschafter nur noch eine "Dépendance" des Reiches: »Elle ne représente plus désormais qu'une sorte de grand Luxembourg accroché aux flancs du Reich et qui n'a plus d'avenir que comme pro-

${ }^{183}$ Siehe Telegramme Nr. 3640-3652 vom 28. September 1938, in: DDF XI/2, Nr. 426 , S. 646-649, hier S. 648.

${ }^{184}$ Telegramme Nr. $3640-3652$ vom 28. September 1938, in: DDF XI/2, Nr. 426, S. 646 649 , hier S. 649.

${ }^{185}$ Siehe die Note de l'ambassadeur de France à Berlin M. François-Poncet vom 28. September 1938, in: DDF XI/2, Nr. 450, S. 671-673, hier S. 672.

${ }^{186}$ Vgl. Note du Département vom 29. September 1938, in: DDF XI/2, Nr. 465, S. 698.

${ }^{187}$ Siehe DDF XI/2, Nr. 481 und 488 sowie DDF XII/2, Nr. 14, 25, 26, 27 und Nr. 52.

${ }^{188}$ Telegramme Nr. $3670-3678$ vom 30 . September 1938, in: DDF XI/2, Nr. 485, S. 721f., hier S. 722.

${ }^{189}$ Siehe auch Telegramm Nr. 3840 vom 13. Oktober 1938, in: DDF XIU/2, Nr. 102, S. 172.

${ }^{190}$ Telegramme Nr. 3727-3729 vom 5. Oktober 1938, in: DDF XII/2, Nr. 27, S. 46. 
tégé et sans doute aussi comme vassal de l'Allemagne ${ }^{191}$. Das sei die Situation heute, die Frankreich nicht ignorieren könne. "Le rapport actuel des forces en Europe lui conseille de ne rien négliger pour pratiquer une politique de détente envers l'Allemagne et chercher à lier ce pays par le plus d'engagements possible, de nature à garantir la paix du continent $\ll$. Gleichzeitig dürfe Deutschland aber keine "confiance prématurée ou trop complète" entgegengebracht werden. André François-Poncet fürchtete, daß das Wort von »Herr Hitler« nur einen »relativen, vorübergehenden Wert« besitze. »Au fond, le Führer reste un aventurier, toujours tendu vers de nouvelles entreprises, toujours avide de nouveaux triomphes, rebelle à l'idée de la saturation et de la modération, de caractère mobile, d'une susceptibilité et d'un orgueil maladifs «. Angesichts eines solchen Partners dürfe Frankreich über die Freude über den geretteten Frieden nicht einschlafen. "Sans délai, elle doit au contraire se mettre au travail, combler les lacunes de ses armements, prendre conscience des dangers encore suspendus sur sa tête, retrouver foi en ellemême et rétablir son prestige ébranlé en donnant à l'extérieur une impression de rénovation spirituelle, de cohésion, de force matérielle et morale ${ }^{192}$. Das war das Programm, das André François-Poncet angesichts der bleibenden Bedrohung seiner Regierung empfahl.

Obwohl die Saarbrücker Rede des Reichskanzlers am 9. Oktober die Befürchtungen des Botschafters bestätigte ${ }^{193}$, war André François-Poncet nach wie vor bereit, den Gesprächsfaden mit Deutschland wieder aufzunehmen. In diesem Sinne muß er Außenminister Bonnet beraten haben, den in Paris inzwischen ein deutscher Unterhändler aufgesucht hatte. André FrançoisPoncet ebnete damit noch den deutsch-französischen Gesprächen den Weg, bevor er Ende Oktober die Reichshauptstadt verließ ${ }^{194}$. Vor diesem Hintergrund nahm sein Abschiedsempfang im Adlerhorst des Reichskanzlers »un tour intéressant et important «: Das Gespräch, an dem auch Außenminister von Ribbentrop teilnahm, drehte sich um die »lendemains de Munich «, die nicht Hitlers Wünschen entsprochen hätten und eine "gefährliche Spannung« zwi-

${ }^{191}$ Depesche Nr. 1060 vom 6. Oktober 1938 (Botschafter François-Poncet an Außenminister Bonnet), in: DDF XII/2, Nr. 45, S. 81-85, hier S. 84.

${ }^{192}$ Ibid. S. 84f.

${ }^{193}$ Siehe Schulthess' Europäischer Geschichtskalender 1938, S. 173-175 sowie Telegramme Nr. 3780-3784 vom 9. Oktober 1938, in: CADN, Ambassade Berlin, Série B, Carton 162 und Depesche Nr. 1075 vom 10. Oktober 1938 (Botschafter François-Poncet an Außenminister Bonnet), in: DDF XIU/2, Nr. 60, S. 110-113.

194 André François-Poncet war Mitte Oktober 1938 zum Botschafter in Rom ernannt worden, vgl. Schulthess' Europäischer Geschichtskalender 1938, S. 393. Diese Versetzung hatte in der Vergangenheit immer wieder zu Spekulationen geführt. Letztlich dürfte die Darstellung André François-Poncets zutreffen, daß er Berlin verlassen wollte. Differenzen über die französische Deutschlandpolitik zwischen Außenminister Bonnet und und seinem Botschafter in Berlin sind jedenfalls nicht auszumachen. 
schen den Großmächten hinterlassen hätte. »Pour l'essentiel«, faßte der Botschafter die Vorschläge des Reichskanzlers zusammen, »M. Hitler s'est déclaré prêt à rechercher les moyens d'améliorer la situation présente et de développer les virtualités d'apaisement et de rapprochement que l'accord du 29 septembre semblait renfermer en lui ${ }^{195}$. Der Reichskanzler schlug vor, einen Grenz- und Konsultationsvertrag zu unterzeichnen. Hitler lehnte auch die Wiederaufnahme des Westpaktgedankens nicht ab. Außerdem schlug er ein "programme d'humanisation de la guerre « vor, das u. a. die Bombardierung offener Städte verbot. Das Angebot erschien dem französischen Botschafter »verführerisch ${ }^{196}$. Gleichwohl wurde André François-Poncet nicht überschwenglich:

Quoi qu'il en soit Hitler est de ces hommes vis-à-vis desquels on ne doit pas se départir d'une extrême vigilance et auxquels on ne saurait accorder qu'une confiance sous réserve. Je n'en déduis pas, pour ma part, qu'il faille se dérober à ses suggestions. En cette circonstance, comme en beaucoup d'autres occasions antérieures, j'estime que l'essentiel est de savoir exactement à quoi s'en tenir et à qui l'on a affaire. Mais il ne s'ensuit pas qu'une attitude d'abstention et de négation soit la vraie ${ }^{197}$.

Schließlich gewinne man auch nicht im Lotto, wenn man nicht wenigstens das Risiko eingehe, ein Los zu kaufen. »C'est un strict devoir que de ne négliger aucune ds voies qui conduisent à la paix. S'il arrive que M. Hitler, par feinte ou par calcul, pénètre assez avant sur ce chemin, il est possible qu'il n'ait plus, par la suite, et même s'il le voulait, le moyen de revenir sur ses pas « ${ }^{198}$. André François-Poncet plädierte also noch am Ende seiner Berliner Amtszeit, Hitler beim Wort zu nehmen, um den Frieden zu retten. Deutschland ergreife die Initiative und Frankreich tue gut daran, sie positiv zu beantworten. »En lui fermant nos oreilles, nous lui procurerions, à notre détriment, l'alibi qu'elle souhaite, peut-être, pour couvrir ses entreprises futures«. Die »Verpflichtungen « hätten zwar eine begrenzte Tragweite, aber wie zum Beispiel ein schriftlicher Verzicht des »Dritten Reiches« auf Elsaß-Lothringen durchaus ihren Wert.

Si ces engagements sont tenus, ils contribueront grandement à détendre l'atmosphère européenne. S'ils ne sont pas tenus, ils chargeront le coupable d'une responsabilité morale qui pèsera lourdement sur son action. La France doit donc en aborder l'examen sans crainte. Peut-être n'est-il pas téméraire, au surplus, de penser que les événements qu'elle vient de vivre auront achevé de la convaincre de la nécessité d'un ordre et d'une cohésion nationale,

195 Telegramme Nr. 3906-3913 vom 19. Oktober 1938, in: CADN, Ambassade Berlin, Série B, Carton 163.

${ }^{196}$ Depesche Nr. 1120 vom 20. Oktober 1938 (Botschafter François-Poncet an AuBenminister Bonnet), in: DDF XII/2, Nr. 197, S. 339-346, hier S. 342.

${ }^{197}$ Ibid. S. 345.

${ }^{198}$ Ibid. 
d'une certaine réforme morale et d'un perfectionnement rapide et rigoureux de son appareil militaire ${ }^{199}$.

André François-Poncet verfolgte am Ende seiner Amtszeit, er verließ Berlin am 1. November, mit einer deutsch-französischen Annäherung nur noch den Zweck, Frankreich - und auch Großbritannien - die notwendige Vorbereitungszeit für den wohl unabwendbaren Krieg mit Deutschland zu verschaffen. Insofern hatten sich - spätestens im Sommer 1938 - die moralischen Motive seiner Deutschlandpolitik in militärische gewandelt. Das Ziel der Annäherung blieb gleich, weil mehr mit dem nationalsozialistischen Deutschland nicht zu erreichen war. Von einer deutsch-französischen Verständigung war keine Rede mehr. Der Botschafter hatte also seine deutschlandpolitischen Vorstellungen in seiner achtjährigen Amtszeit in Berlin grundlegend verändert, wie abschließend zusammenfassend darzustellen sein wird.

199 Depesche Nr. 1120 vom 20. Oktober 1938 (Botschafter François-Poncet an Außenminister Bonnet), in: DDF XU/2, Nr. 197, S. 339-346, hier S. 346. Zum weiteren siehe Hans F. BELLSTEDT, »Apaisement« oder Krieg. Frankreichs Außenminister Georges Bonnet und die deutsch-französische Erklärung vom 6. Dezember 1938, Bonn 1993. 
